\title{
COMPRESSION AND STRENGTH CHARACTERISTICS OF TWO SILTS OF LOW AND HIGH PLASTICITY
}

Georgiannou, Vassiliki N., Ph.D. (corresponding author)

Professor, Civil Engineering, National Technical University of Athens,

vngeor@civil.ntua.gr

Coop, Matthew R., DPhil

Professor, Department of Civil, Environmental and Geomatic Engineering, University

College London, m.coop@ucl.ac.uk

Altuhafi, Fatin N., Ph.D.

Research Associate, Earth Sciences, University College London, f.altuhafi@ucl.ac.uk

Lefas, Demetrios I., BA, MEng (Cantab)

PhD Candidate, Department of Engineering, University of Cambridge, dl467@cam.ac.uk

\section{Abstract}

The potential for enhanced strength or stiffness arising from the microstructure of natural silty soils compared to their reconstituted state is examined using the framework proposed by Burland for clays, to assess to what extent it can be used for silts. A detailed study performed on two clayey silts of low and high plasticity respectively, in their intact and reconstituted state, is used to illustrate the different response of the silts compared to clays in terms of compressibility and strength e.g. multiplicity and shape of the normal compression lines and strong dilative tendencies during undrained and drained shearing. This paper shows that the response of the reconstituted silts can be used as a reference to identify the influence of the microstructure on the compressibility and strength of the intact silts. The results are found to give clear signs of structure in both compression and shearing only for the low plasticity silt. Stiffness measurements corroborate these findings.

Key words: Silts, Compressibility, Shear Strength

\section{INTRODUCTION}

To assess the influence of microstructure, first recognized by Terzaghi 1941, Skempton and Northey 1952, proposed the comparison of the response of natural intact and reconstituted clays. Burland 1990, presented a framework which uses the 
response of reconstituted clays to normal compression and shearing as a reference for understanding the properties of the parent intact clays. The enhanced strength and/or stiffness arising from the microstructure of the natural material compared to its reconstituted state has since been observed repeatedly (e.g. Hight et al. 1992; Smith et al. 1992; Allman and Atkinson 1992; Burland et al. 1996; Cotecchia and Chandler 1997; Cotecchia and Chandler 2000; Georgiannou and Burland 2001; Mitchell and Soga 2005; Gens 2011) with some exceptions for which there was no enhancement, as in the case of the glacial till tested by Atkinson and Little 1988, in which the natural and reconstituted Hvorslev lines coincide. However, much less is known about the potential for enhanced strength or stiffness in silty soils, which is partly because they are much less frequently tested and perhaps partly because it is not certain whether frameworks such as that of Burland might be applied to such soils. This paper seeks to address to what extent these techniques may be used.

Burland 1990, defined a thoroughly mixed clay at a moisture content of between 1.2-1.5 times the natural clay liquid limit, to form a slurry, as reconstituted and termed its mechanical properties as 'intrinsic' which are inherent to the material and independent of its natural state i.e. initial differences in void ratio at low stresses $(<100 \mathrm{kPa})$ are erased at higher stresses, encountered in the field, and all normal compression lines converge to a unique NCL. He also showed that different compression lines for a wide range of reconstituted clays lying above the $A$ line form a unique line, termed the intrinsic compression line, ICL, when normalized with respect to the void index

$$
I_{V}=\frac{e-e_{100}^{*}}{e_{100}^{*}-e_{1000}^{*}}
$$

where $e_{100}^{*}$ and $e_{1000}^{*}$ are the intrinsic void ratios corresponding to $\sigma^{\prime}{ }_{V}=100 \mathrm{kPa}$ and $1000 \mathrm{kPa}$ respectively. 
Although reconstituted clays with Atterberg limits lying above the A line like those examined by Burland 1990, and Burland et al. 1996, confirm the concept of a unique NCL and CSL, a large number of natural soils show non-convergence of the NCLs in their reconstituted state, even at high stresses. Such soils have been described as transitional in the literature. Martins et al. 2001 concluded that transitional soil behavior is a characteristic of gap-graded soils. However, this type of behavior can also be observed in well-graded materials and silty soils (e.g. Nocilla et al. 2006), and so this is another aspect that has been addressed in this investigation, since if present, it would affect how structure might be quantified.

Hong et al. 2010, showed that for a number of reconstituted clays, lying slightly above the A line, the NCL at higher initial mixing water content, $w_{0}$, lies above the corresponding NCL at lower $\mathrm{w}_{0}$ for stresses up to $1600 \mathrm{kPa}$ indicating a transitional type of behavior; $\mathrm{w}_{0}$ varies between 0.7-2 times the natural clay liquid limit. Hence Burland's 'intrinsic' properties do not represent inherent soil properties. However, when the NCLs are normalized with respect to the void index, $I_{v}$, a unique normalized line is obtained, almost identical to the ICL proposed by Burland. Hong et al. 2013, extended this normalization procedure to the undrained shear strength of the reconstituted clays.

In this paper the fundamental behavior of two natural silts lying just below the A line is examined. Interest in these materials is prompted by ground failures occurring in low-plasticity silts and clays under seismic loading. Boulanger and Idriss, 2006, discussed fine-grained soils transition from behavior that is more fundamentally like sands to behavior that is more fundamentally like clays and recommended that fine-grained soils be classified as "sand-like" if $\mathrm{Pl}<7$, and "claylike" if $\mathrm{Pl}>7$. Of the two silts examined herein one is of low $(\mathrm{Pl}=6)$ and the other of high $(\mathrm{Pl}=25)$ plasticity hence their behavior is expected to differ. The response of the silts is evaluated in terms of their compressibility and strength characteristics in both 
the reconstituted and intact state. Stark et al. 1994, 2000, found that reconstituted and intact silts for sites in Mississippi had significantly different response due to the enhanced structure of the latter.

A normalization procedure like the one used successfully for clays (Burland, 1990), as a means to normalize all of the compression curves of reconstituted soils to be the same for ease of comparison, was adopted for the silts under consideration. This highlights: i) differences in compressibility with varying plasticity index for the reconstituted silts; ii) comparison of the normalized 'intrinsic' compression lines of the two silts with that obtained by Burland for clays; iii) the enhanced resistance of the intact material to compression and shearing compared to its reconstituted counterpart; the shear behavior is examined for normally and overconsolidated states as described in the critical state framework (Roscoe, et al. 1958). The normalization procedure takes account of differences in void ratio at e.g. peak strength for the reconstituted and intact silt. In this way the influence of the microstructure in the intact silt can be isolated and assessed. The underlying method of comparing intact with reconstituted soils is one that is commonly applied to all types of soils, clays and sands (e.g. Cuccovillo \& Coop, 1999). Comparison of the behaviour of intact and reconstituted soils highlights the effects of structure, highlights how existing methods may be used, and how the behavior is different between a low and higher plasticity silt. Significant effects of structure are identified in one silt only. The aim of the paper is to provide fundamental knowledge on the compressibility and strength of silts apart from assessing the influence of microstructure in the natural intact material. Moreover, the variation of stiffness with strain for the intact silt samples is measured at various stress levels. 


\section{MATERIAL PROPERTIES AND TESTING PROCEDURES}

One of the materials tested is a low plasticity marl from the base of the Corinth Canal (Kavvadas et al. 2003) and the other is a high plasticity clayey silt obtained from a location in central Greece, near the city of Lamia, during the construction of the E65 motorway, and will be refered to from this point onwards as Lamia soil. The Marl is a neogene formation of hard calcareous clayey silts with a calcium carbonate content of around $75 \%$. Calcite acts as a cementing agent between individual quartz and clay particles and is responsible for the characteristic properties of the marl. The gradings of the two soils are rather uniform with a small clay content of less than $15 \%$ as indicated in Table 1 where gradation data are presented (see also Fig. S1). Table 1 includes plasticiy properties (Atterberg limits) which are relatively higher for Lamia soil compared to the Marl.

The Lamia soil was mineralogically studied by means of X-ray diffraction (XRD) which indicated the presence of high amount of quartz, feldspars and swelling clay minerals as shown in Fig. 1, in the black spectrum. The latter were documented after glycol treatment; the shift of the (100) main reflection from $d \sim 14 \AA$ to $d \sim 17 \AA$ in the red spectrum in Fig. 1, confirms that the swelling mineral is montmorillonite. The presence of montmorillonite justifies the retained water content at liquid and plastic limit which when marked on the A graph indicate a high plasticity silt lying close to the A-line (see Fig. S2).

Large blocks of the Marl were extracted from the base of the canal $70 \mathrm{~m}$ deep while blocks of Lamia were less deeply buried; obtained from a depth of $5 \mathrm{~m}$ after the removal of the overlying deposits. The blocks, 50 to $60 \mathrm{~cm}$ high, were wrapped with cling film and covered with wet cloth. The samples were stored in a chamber in which water below the level of the samples ensured a humid environment around them. Triaxial specimens $38 \mathrm{~mm}$ in diameter and $76 \mathrm{~mm}$ in height were hand trimmed in a soil lathe from the block samples. The tested soils were initially saturated, and 
the $B$ values measured in the triaxial specimens were in excess of 0.95 . The initial mean effective stress in each specimen, $\mathrm{p}_{i}$, was measured by applying a cell pressure and allowing the pore pressure to come to equilibrium, usually involving a period of $24 \mathrm{~h}$. Values of around $90 \mathrm{kPa}$ and $70 \mathrm{kPa}$ were obtained for Lamia and Marl respectively, representing the maximum sustainable suction which, because of their silty composition, can be substantially less than the in situ value (Hight and Georgiannou 1995). Specimens were subsequently consolidated to a range of effective stresses.

Reconstituted specimens were hand trimmed in the soil lathe from reconstituted cylindrical samples $23 \mathrm{~cm}$ in diameter and $40 \mathrm{~cm}$ in height, shown as an inset in Fig. S1, for Lamia soil. These were exracted from a cylindrical metal tube, forming the consolidometer, after being subjected to one dimensional consolidation. The reconstituted materials were formed by mixing each natural soil at 1.3 times its liquid limit to the state of slurry, which was subsequently poured into the consolidometer and allowed to consolidate initially under its own weight and then under compression stresses of $12.5 \mathrm{kPa}, 25 \mathrm{kPa}, 50 \mathrm{kPa}$ and $100 \mathrm{kPa}$. The Marl was also consolidated up to $200 \mathrm{kPa}$. Finally, the cylindrical sample was unloaded to $50 \mathrm{kPa}$ before it was exctracted from the consolidometer. Specimens were prepared from this sample at $38 \mathrm{~mm}$ and/or $50 \mathrm{~mm}$ diameter and height to diameter ratio of 2 . The reconstituted specimens were fully saturated with B values of around 1 . The specimens retained their effective stress since the initial mean effective stress measured in the triaxial was around $p_{i}^{\prime}=50 \mathrm{kPa}$.

Laboratory tests were carried out in computer controlled Bishop and Wesley (1975) triaxial stress path cells with an accuracy of $\pm 0.5 \mathrm{kPa}$ in pressure and $\pm 0.1 \mathrm{~N}$ in load measurements. The instrumentation of the triaxial cells included a pair of local strain measurement transducers, either the axial strain electro-level inclinometers (Burland and Symes, 1982) or submersible linear variable differential transducers 
(LVDTs) mounted diametrically opposite over a central axial gauge length of the specimens. The shearing rate was $4.5 \% /$ day for the undrained tests and $1 \%$ /day for the drained tests. Apart from the top and bottom porous stones filter paper side drains were used for Lamia but not for Marl specimens due to its higher permeability.

\section{COMPRESSIBILITY CHARACTERISTICS}

\section{Reconstituted Materials}

The normal compression curves for specimens loaded from various slurry states in the standard oedometer are shown in Fig. 2. Fig. 2(a) shows the compression data of reconstituted Lamia specimens which were obtained by mixing the soil at various water contents corresponding to 0.81 to 1.41 times its liquid limit to form slurries of the natural material. Fig. 2(b) shows the compression data of reconstituted Marl specimens which were mixed at 0.78 to $1.54 x$ LL. Unlike typical behavior of a clay, where the curves converge at normal stresses higher than $100 \mathrm{kPa}$, these silty materials show no sign of convergence for normal stresses as high as $6 \mathrm{MPa}$. This is similar to the transitional behavior associated with some well graded silts (Nocilla et al. 2006; Altuhafi et al. 2010). The curves appear to be nearly parallel for the Marl. However, the lines converge for Lamia soil with initial mixing moisture contents higher than $1.2 \times L L$ at high stresses of around $1 \mathrm{MPa}$. It should be noted that at the latter mixing contents both materials are so weak that they cannot support the oedometer top cap. As a result the first loading stage included only the porous stone, followed by the top cap and a loading sequence by which the applied pressure at any stage is double that at the preceding stage, as described in the previous section. Each loading stage lasted 24h. For the Marl two sets of data are included in Fig. 2(b), corresponding to a recent and an older (2008) sampling session, confirming lack of convergence for the NCLs. 
Although the normal compression curves for both materials are not converging they can be normalized with respect to the vertical axis by replacing e with the void index $I_{v}=\left(e-e_{100^{*}}\right) /\left(e_{100^{*}}-e_{1000^{*}}\right)$ due to their similarity in shape; $e_{100^{*}}$ and $\mathrm{e}_{1000^{*}}$ are defined as the void ratios on each compression line corresponding to

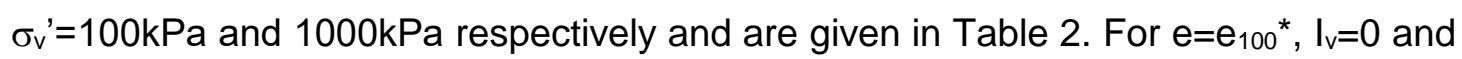
for $e=e_{1000}{ }^{*}, I_{v}=-1$, hence differences in the shape of the normalized compression lines can be highlighted. The normalized compression curves for differing initial water contents merge to an almost unique line for normal stresses higher than $100 \mathrm{kPa}$ when plotted in terms of $I_{v}$ for Lamia soil as shown in Fig. 3(a). Moreover, a comparison with the normalized curve obtained by Burland for a number of reconstituted sedimentary clays, depicted as a dotted line in Fig. 3(a), indicates that despite the different grading of the Lamia silt the normalized curves nearly coincide highlighting the prominent role of the silt's high plasticity. However, this is not the case for the low plasticity Marl as the normalized curves present a different concave downward shape as shown in Fig 3(b). The normalized compression curves of the Marl do not only show a different behavior within the range $100-1000 \mathrm{kPa}$, but an even more pronounced difference outside this range can also be observed. It is interesting that although Lamia soil lies slightly below the A line in the plasticity chart as shown in Fig. S2, it has a similar ICL with sedimentary clays lying above the A line (Burland 1990) or on the A line (Hong et al. 2010). The observed deviation of the ICL of the Marl, also lying slightly below the A line, indicates that due to its low plasticity and possibly its coarser grading it is behaving more like a sandy silt. This is similar to the results obtained by Altuhafi et al. 2010 on a well graded glacial sediment dominated by non-plastic silt, in which a similar concave downward compression curve was observed for the sediment, or by Carrera et al. 2011 on sand and silt mixtures. 
To quantify the degree of convergence of the normal compression curves, or lack of it, Ponzioni et al. 2014, introduced the parameter $\mathrm{m}$ which is defined as the gradient of the diagram of the specific volume, $v=1+e$, at low stress (e.g. 20kPa) against the specific volume at high stress (e.g. $3000 \mathrm{kPa}$ ) on a compression curve. In Fig. 4 these plots are shown for both Lamia and Marl soils. The gradient of the data for Lamia is nearly zero indicating full convergence within the range $1.15-1.41 \mathrm{xLL}$. For the Marl however, there is a clear positive gradient, $m=0.5$, confirming lack of converge and hence sensitivity to initial mixing water content. The lack of convergence of the normal compression curves can be indicative of non-unique critical state lines (Ferreira and Bica 2006; Shipton and Coop, 2015).

In Fig. 5 the normal compression curves obtained from testing reconstituted specimens from slurry states in the standard oedometer are compared with the corresponding curves obtained for specimens which were trimmed from the large sample reconstituted from a similar slurry state, namely at a mixing content of approximately $w_{i}=1.3 x L L$, in the consolidometer by initial loading to a vertical stress of $100 \mathrm{kPa}$ and $/$ or $200 \mathrm{kPa}$ and subsequent unloading to $50 \mathrm{kPa}$, prior to extruding. For stresses exceeding the preconsolidation stress applied in the consolidometer the normal compression curves nearly coincide indicating that reconstitution is not affected by the size of the oedometer or the consolidometer. The initial water content for the trimmed specimens, after swelling in the consolidometer, was $w_{0}=40-41 \%$ and 27\% for Lamia and Marl, shown in Fig. 5(a) and 5(b) respectively. Ideally to quantify structure the mixing water content used to form the slurry should be the same as that for the intact soil when it was deposited, but this is not easily known. Skempton 1970, and Buchan and Taylor Smith, 1999, presented the water contents of recent deposits at around $0.25 \mathrm{~m}$ under the sea bed; they varied between $1.5 \times \mathrm{LL}-\mathrm{LL}$ and $1.8 \mathrm{xLL}-\mathrm{LL}$ comparable with $1.25 x \mathrm{xL}$ to $1.5 \times \mathrm{LL}$ suggested by Burland for reconstitution. For Lamia the compression lines appear to converge in the range $(1.15-1.44) x L L$ but this 
is not the case for the Marl which in a narrower range (1.26-1.44)xLL still shows some lack of convergence in Fig. 4. Given that the loosest homogeneous structure was observed for the Marl at the lower end of the range, a mixing water content of 1.3 was adopted for reconstitution.

\section{Intact Materials}

The oedometer compression curves for specimens prepared from the block samples of the natural materials in their intact state are shown in Fig. 6(a) and 7(a) for Lamia and Marl respectively. It appears that the Lamia soil soon reaches an obvious normal consolidation curve while normal stresses higher than $3000 \mathrm{kPa}$ are required for the Marl which are significantly higher than the effective overburden and this is strong indication of particle bonding. A similar observation was made by Stark et al. 2000, on Mississippi loess.

A normalization with respect to the void index $\mathrm{I}_{\mathrm{v}}$, was used in order to compare the intact and reconstituted materials. The values of $e_{100}{ }^{*}=1.025$ and

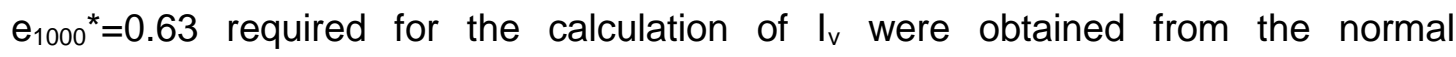
compression curve of the 'reconstituted' in the consolidometer Lamia material shown in Fig. 5(a), the same material used to form the triaxial specimens. It should be noted that the normal compression curve was extended back to $100 \mathrm{kPa}$ parallel to the normal compression curves of the oedometer slurries to define $\mathrm{e}_{100^{*}}$. For the Marl the normal compression line of the material reconstituted from slurry in the standard oedometer at 1.26 times the liquid limit of the natural soil was used for normalization since the 'reconstituted' in the consolidometer specimen had a preconsolidation pressure of $200 \mathrm{kPa}$ in Fig. $5(\mathrm{~b})$. The corresponding $\mathrm{e}_{100^{*}}=0.736$ and $\mathrm{e}_{1000^{*}}=0.620$ values are included in Table 2. The aforementioned normal compression curves will also be used for the normalization of the triaxial test data to define critical state parameters for each material. 
Fig. 6(b) shows the results of normalization of the normal compression curves for Lamia soil with respect to $I_{v}$. The curve for the reconstituted material $\left(w_{0}=39.5 \%\right)$ merges at stress levels higher than $200 \mathrm{kPa}$ with the curve obtained for the specimen formed from slurry in the oedometer. Moreover, both are in turn similar to the curve obtained for sedimentary clays (Burland 1990) also included in Fig. 6(b) as a dotted line. The normal compression curves of the intact material do not cross and appear to converge with the ICL line at large stresses. The results indicate that the intact material has not enhanced microstructure compared to the reconstituted material possibly due to disturbance at shallow depth.

On the contrary the oedometer compression curves for the intact Marl, shown in Fig. $7(b)$, cross the ICL indicating the presence of microstructure in the intact material probably due to its high calcium carbonate content. Both the arrangement of the soil particles and the bonding between them describes microstructure according to Mitchell, 1976. It should be noted that had the ICL proposed for sedimentary clays, shown as a dotted line in Fig. 7(b), been adopted the enhanced structure of the intact material would have been masked.

\section{SHEAR BEHAVIOUR IN THE TRIAXIAL APPARATUS $\underline{\text { Reconstituted Materials }}$}

Fig. 8 (a) shows the effective stress paths, plotted in terms of shear stress, $t=\left(\sigma_{1^{-}}\right.$ $\left.\sigma_{3}\right) / 2$, against mean effective stress, $s^{\prime}=\left(\sigma_{1}{ }^{\prime}+\sigma_{3}{ }^{\prime}\right) / 2$, representing the state of stress in a Mohr diagram, for undrained (CIU) tests on specimens of Lamia soil isotropically consolidated in the triaxial apparatus from an initial effective stress of $50 \mathrm{kPa}$ over a range of effective stresses. The peak strengths for drained tests (CID) have been marked by crosses in the figure. The overconsolidated specimens were all swelled from an initial effective stress of $400 \mathrm{kPa}$. In Table 3 the specimen characteristics are 
summarized. For both normally and overconsolidated specimens failure took place after bulging along a single failure plane. The stress paths for the normally consolidated specimens are not typical of clay type material in that they turn sharply to the right and climb up the failure envelope slightly; a response associated with the moderate dilative tendencies indicated by the pore pressures at strains larger than 5\% shown in Fig. 9(b) for a typical test. However, the stress-strain curve in Fig. 9(a) reaches a plateau at large strains, as observed in reconstituted clays. The stressstrain and excess pore water pressure against strain curves show reasonably flat peaks and well-defined critical states at strains larger than $10 \%$ as shown in Fig. S3 (a) and (b), with no marked reduction in strength at large strains, while the undrained tests on the overconsolidated specimens exhibit post-peak strength reduction, corresponding to dilative tendencies for the specimen with $\mathrm{OCR}=4$ only. Similarly, the specimen tested under drained conditions at the highest OCR shows brittleness (Fig. 3S (c) and (d)).

The peak strengths of the overconsolidated specimens for undrained and drained tests appear to lie in general slightly above the intrinsic failure line defined by the peak strengths of the normally consolidated specimens. The line can be seen to be slightly curved close to the stress origin, a feature observed in reconstituted clays (Burland et al. 1996). In the range s' $=100 \mathrm{kPa}$ to $400 \mathrm{kPa}$ the value of $\phi_{\mathrm{cv}}{ }^{*}=21.8^{0}$.

The reconstituted specimens of the Marl failed mainly by bulging although at very large strains a failure plane could be occasionally observed. Specimen characteristics are shown in Table 4. Fig. 8(b) shows the effective stress paths and peak drained strengths marked as dots. Specimens of the Marl show stress paths climbing up the failure envelope at a relatively constant stress ratio, $t / s^{\prime}$, accompanied by strong dilative tendencies at strains less than $5 \%$ as can be observed in Fig. 8(b) and 9(b) respectively, probably due to its coarse silt fraction. Fig. 9 shows the stress-strain and excess pore water pressure against strain curve 
for a typical undrained test while Fig. S4 shows all tests on reconstituted Marl included in Table 4. Unlike Lamia the Marl shows phase transformation like a sand (Ishihara 1975). However, dilative tendencies abruptly reduce as peak strength is approached and excess pore water pressure remains nearly constant at positive values as nearly flat peaks, indicating critical state, develop at strains of around $10 \%$ in Fig. 9. This is distinctly different behavior to a typical sand which requires extremely high strains $(>30 \%)$ to reach critical state and confining pressures (>2000kPa) to develop positive excess pore water pressure at critical state. A common failure envelope was defined for undrained and drained tests with $\phi_{\mathrm{cv}}{ }^{*}=36.8^{0}$. It appears that although Lamia soil shows a clay-like behavior, the Marl shows a transition phase with characteristics of silt or sandy-like behavior. Hyde et al. 2006, observed similar response for reconstituted specimens of a low-plasticity silt $(\mathrm{PI}=6 \%)$ under undrained monotonic loading namely, phase transformation followed by dilative behavior until an ultimate peak deviator stress was reached.

Fig. 10 shows the Hvorslev failure surface for the reconstituted materials plotted on a graph of $t / \sigma_{v e}^{\prime}$ against $s^{\prime} / \sigma_{v e}^{\prime}$. The compression curves described in Fig. 5 were used for normalization of the shearing data with respect to the equivalent normal stress on the ICL corresponding to the void ratio at peak shear stress, $\sigma_{\mathrm{ve}}{ }^{*}$. The experimental points for Lamia tests in Fig. 10(a) lie on a unique straight line having Hvorslev strength parameters $\phi_{\mathrm{e}}{ }^{*}=23.8^{0}$ and $\kappa^{*}=0.04$. These intrinsic strength parameters will be compared with the strength parameters of the material in its natural intact state in the next section. The corresponding parameters for the Marl shown in Fig. $10(\mathrm{~b})$ are $\phi_{\mathrm{e}}{ }^{*}=31.7^{0}$ and $\kappa^{\star}=0.06$

\section{Intact Materials}

Specimen characteristics of the intact materials are included in Tables 3 and 4 for Lamia and Marl respectively. The initial void ratio, $e_{i}$, shown in the Tables was 
calculated from the moisture content measured for the block $\left(w_{\mathrm{i}} \sim 30 \%\right.$ and $\sim 25 \%$ for Lamia and Marl respectively) before consolidation in the triaxial to $e_{0}$ prior to shearing. Fig. 11 shows typical CIU tests on intact specimens taken from block samples of Lamia high plasticity silt. The effective stress paths in Fig. 11(a) show initial contraction followed by dilation. The strong dialtive tendency well before peak is more pronounced in those specimens tested at $300 \mathrm{kPa}$ and $500 \mathrm{kPa}$. However, the stress-strain curves shown in Fig. 11(b) are flat and do not show brittleness at least for axial strains up to $10 \%$. The excess pore water pressures shown in Fig. 11(c) indicate that dilative tendencies take over long before peak at about $5 \%$ axial strain and continue thereafter. Such dilative tendencies can be attributed to the dominance of silt in this soil. The samples after slight bulging developed single slip surfaces at $50-53^{0}$ to the horizontal followed by a conjugate surface at large strains.

In Fig. 12 the intact failure line for the Lamia soil has been drawn through the peak strengths of the undrained tests. It can be seen that the peak failure envelope for the intact material lies sligthly above the critical state line defined for the reconstituted material while intact strengths higher than the critical state are observed. In Fig. 13 a comparison is made between the peak strengths of intact and reconstituted material on a normalized graph of $t / \sigma_{v e}^{\prime}$ against $s^{\prime} / \sigma_{v e}^{\prime}$. The normal compression line of the reconstituted specimens was used for the normalization as discussed earlier. It can be seen that the Hvorslev failure line for the intact material nearly coincides with the corresponding intrinsic line. The influence of microstructure on the intact strength can be assessed by comparing the intact Hvorslev strength parameters with the equivalent intrinsic values. The similarity of the Hvorslev failure lines for the intact and the reconstituted material suggests there is no enhanced structure in the natural state of the material. This finding is also consistent with the observation made in Fig. 6(b) that the normal compression line of the intact material does not cross the ICL. 
For the intact Marl, a series of constant p' tests on specimens anisotropically consolidated along a contant stress ratio $\left(\sigma \sigma^{\prime} / \sigma_{1}{ }^{\prime}=0.46\right)$ was performed aiming at studying strength characteristics of the Marl at relatively low stresses. The corresponding stress-strain and volumetric against axial strain curves are shown in Fig. 14. Strong dilation is evident which is arrested as strain localization takes place and a failure plane is formed at around $60^{\circ}$ to the horizontal. Georgiannou and Burland 2006, examined the same tests and concluded that the initiation of strain localisation takes place at axial strains that are significantly greater than the axial strains for peak strength. Given this observation the peak strengths of the intact and reconstituted marl are compared in Fig. 15 after normalization with respect to $\sigma^{\prime}$ ve* The Hvorslev line for the intact material lies above the corresponding line for the reconstituted material and well above the strengths at critical state indicating the presence of an enhanced microstructure in the intact material as already indicated by the normal compression lines shown in Fig. 7(b). The Hvorslev strength parameters for the intact Marl are $\phi_{\mathrm{e}}^{\prime}=34.6^{0}, \kappa^{*}=0.28$.

Fig. 16 shows the variations in normalized shear modulus with shear strain derived from the local strain measurements for Lamia and Marl respectively. For specimens consolidated to different consolidation pressures, the secant stiffness, $E_{s}$, has been calculated from the deviator stress, $q=\sigma_{1}-\sigma_{3}$, against shear strain, $\varepsilon_{s}=2 / 3\left(\varepsilon_{1}\right.$ $\left.\varepsilon_{3}\right)=\varepsilon_{1}-\varepsilon_{v} / 3$, curves where $\varepsilon_{1}=$ axial and $\varepsilon_{v}=$ volumetric strain. The shear modulus, $G$, was calculated as $E_{s} / 3$ assuming the soil to be isotropic. Stiffnesses normalized with respect to initial mean effective stress in Fig. 16(a) define a narrow band for Lamia, which is also a sign of small interparticle bonding. The band is wider for the Marl in Fig. 16 (b) probably due to some bonding. Normalization with respect to $p^{\wedge(0.3-0.5)}$ did not bring the curves any closer. Comparison of these values with stiffness measurements on various natural soils is made by Georgiannou et al. 2011 . 


\section{CONCLUSIONS}

The behavior of two natural silts is examined within the framework describing the response to normal compression and shearing for reconstituted clays. In their reconstituted state these materials are very sensitive to the moisture content used to form the slurry.

When normalized with respect to $I_{v}$ the ICL for the high plasticity silt coincides with the ICL obtained for reconstituted natural sedimentary clays; however, the low plasticity silt exhibits a different ICL concave downwards.

Similarly, the mechanical response to axisymmetric loading of both soils reconstituted at a mixing water content of around $1.3 \times \mathrm{LL}$ shows that although the high plasticity silt adheres to a clay-like behavior, the low plasticity silt shows a transition phase with characteristics of sand-like behavior.

Nevertheless, the response of the reconstituted materials can be used as a reference to identify the influence of the microstructure on the compressibility and strength of the intact materials. The comparison leads to the overall conclusion that in both compression and shearing the Marl shows clear signs of structure like many natural soils, but the Lamia soil does not; this could be due to its shallow depth and lack of enhanced natural microstructure contrary to the Marl.

The intact Marl exhibits higher stiffness when normalized with respect to mean effective stress compared to Lamia. Normalized stiffness defines a narrow band for Lamia while for the Marl the observed variation may be attributed to its structure. 


\section{REFERENCES}

Allman, M. A., and Atkinson, J. H. (1992). "Mechanical properties of natural Bothkennar clay." Géotechnique, 42(2), 289-301.

Altuhafi, F., Baudet, B. A., and Sammonds, P. (2010). "The mechanics of subglacial sediment: an example of new "transitional behaviour"." Canadian Geotechnical J., 47(7), 775-790.

Arroyo, M., Ciantia, M., Castellanza, R., and Gens, A. (2011). "A soft-rock model for cement-improved clays." Proc., $15^{\text {th }}$ European Conference on Soil Mechanics and Geotechnical Engineering-Geotechnics of Hard Soils-Weak Rocks, Athens, Greece. Atkinson, J. H., and Little, J. A. (1988). "Undrained triaxial strength and stress-strain characteristics of a glacial till soil." Canadian Geotechnical J., 25(3), 428-439.

Bishop, A. W., and Wesley, L. D. (1975). "A hydraulic triaxial apparatus for controlled stress path testing." Géotechnique, 25(4), 657-670.

Boulanger, R. W., and Idriss, I. M. (2006). "Liquefaction susceptibility criteria for silts and clays." J. Geotech. Geoenviron. Eng. ASCE, 132(11), 1413-1426.

Buchan, S., and Taylor Smith, D. (1999). "Deep-sea sediment compression curves: some controlling factors, spurious overconsolidation, predictions, and geophysical reproduction." Marine Georesources \& Geotechnology, 17(1), 65-81.

Burland, J. B., and Symes, M. (1982). "A simple axial displacement gauge for use in the triaxial apparatus." Géotechnique, 32(1), 62-65.

Burland, J. B. (1990). "On the compressibility and shear strength of natural clays." Géotechnique, 40(3), 329-378.

Burland, J. B., Rampello, S., Georgiannou, V. N., and Galabresi, G. (1996). "A laboratory study of the strength of four stiff clays". Géotechnique, 46(3), 491-514.

Carrera, A., Coop, M., and Lancellotta, R. (2011). "Influence of grading on the mechanical behaviour of Stava tailings." Géotechnique, 61(11), 935-946. 
Chandler, R. J. (2000). "Clay sediments in depositional basins: the geotechnical cycle." Q. J. of Eng. Geol. and Hydrogeology, 33(1), 5-39.

Cotecchia, F., and Chandler, R. J. (1997). "The influence of structure on the prefailure behaviour of a natural clay." Géotechnique, 47(3), 523-544.

Cuccovillo, T., and Coop, M. R. (1999). "On the mechanics of structured sands". Géotechnique, 49(6), 741-760.

Ferreira, P. M. V., and Bica, A. V. D. (2006). "Problems of identification of the effects of structure and critical state in a soil with transitional behaviour." Géotechnique, 56(7), 445-454.

Georgiannou, V. N., and Burland, J. B. (2001). "A laboratory study of post-rupture strength." Géotechnique, 51(8), 665-675.

Georgiannou, V. N., and Burland, J. B. (2006). "A laboratory study of slip surface formation in an intact natural stiff clay." Géotechnique, 56(8), 551-559.

Georgiannou, V. N., Ferreira, P. M. V., and Altuhafi, F. (2011). "Measurements of stiffness of Greek stiff soils." Proc. of the $15^{\text {th }}$ European conference on soil mechanics and geotechnical engineering, Athens 1, 185-190.

Hight, D. W., Bond, A. J., and Legge, J. D. (1992). "Characterization of the Bothkennar clay: an overview." Géotechnique, 42(2), 303-347.

Hight, D.W., and Georgiannou, V.N. (1995). "The Effect of Sampling on Clayey Sands." Geotechnique, 45(2), 237-247.

Hong, Z. S., Yin, J., and Cui, Y. J. (2010). "Compression behavior of reconstituted soils at high initial water contents." Géotechnique, 60(9), 691-700.

Hong, Z. S., Bian, X., Cui, Y. J., Gao Y. F., and Zeng, L. L. (2013). "Effect of initial water content on undrained shear behavior of reconstituted clays." Géotechnique, 63(6), 441-450.

Hyde, A. F. L., Higuchi, T., and Yasuhara, K. (2006). "Liquefaction, cyclic mobility, and failure of silt." J. Geotech. Geoenviron. Eng. ASCE, 132, 716-735. 
Ishihara, K., Tatsuoka, F., and Yasuda, S. (1975). "Undrained deformation and liquefaction of sand under cyclic stresses". Soils Found. 15, (1), 29-44.

Kavvadas, M., Anagnostopoulos, A. G., Georgiannou, V. N., and Bardanis, M. E. (2003). "Characterisation and engineering properties of the Corinth marl." Proc. of a Workshop on Characterisation and Engineering Properties of Natural Soils, Singapore, T.S. Tan et al., 2nd edn., 1435-1459, A.A. Balkema Publishers.

Martins, F. B., Bressani, L. A., Coop, M. R., and Bica, A.V.D. (2001). "Some aspects of the compressibility behavior of a clayey sand." Canadian Geotechnical J., 38(6), 1177-1186.

Mitchell, J. K. (1976). Fundamentals of soil behavior. New York: Wiley.

Nocilla, A., Coop, M.R. and Colleselli, F. (2006). "The mechanics of an Italian silt; an example of 'transitional' behavior." Geotechnique, 56(4), 261-271.

Picarelli, L., Di Maio, C., Olivares, L., and Ureiuoli, G. (1998). "Properties and behaviour of tectonized clay shales in Italy." Proceedings of the $2^{\text {nd }}$ international symposium on the geotechnics of hard soils - soft rocks, Napoli 3, 1211-1242.

Ponzoni, E., Nocilla, A., Coop, M. R., and Colleselli, F. (2014). "Identification and quantification of transitional modes of behavior in sediments of Venice lagoon." Geotechnique, 64(9), 694-708.

Roscoe, K. H., Schofield, A. N., and Wroth, C. P. (1958). "On the yielding of soils." Géotechnique, 8, 22-53.

Shipton, B, and Coop, M. R. (2015), "Transitional Behaviour in Sands with Plastic and Non-plastic Fines." Soils and Foundations 55(1), 1-16.

Skempton, A. W. (1970). "The consolidation of clays by gravitational compaction." $Q$. J. Geol. Soc. 125(1-4), 373-411.

Smith, P. R., Jardine, R. J. and Hight, D. W. (1992). "The yielding of Bothkennar clay." Géotechnique, 42(2), 257-274. 
Skempton, A. W. and Northey, R .D. (1952). "The sensitivity of clays." Geotechnique, 3, 30-53.

Stark, T. D., Ebeling, R.M., and Vettel J.J. (1994). "Hyperbolic Stress-Strain Parameters for Silts," Journal of Geotechnical Engineering, ASCE, 120(2), 420-441.

Stark, T.D., Ebeling, R.M., and Daly K.R. (2000). "Stress-Strain Behavior and Hyperbolic Parameters of Structured Silt," Proc. of Specialty Conference GEO-Denver, ASCE, Denver, CO.

Terzaghi, K. (1941). "Undisturbed clay samples and undisturbed clays." J. Boston Soc. Civ. Engrs, 28(3), 45-65. 
TABLES

Table 1: Gradation data and index properties

\begin{tabular}{|c|c|c|c|c|c|c|c|c|c|}
\hline & \multicolumn{5}{|c|}{ Percentage passing (\%) } & \multirow[t]{2}{*}{$\mathrm{G}_{\mathrm{s}}$} & \multirow[t]{2}{*}{ LL (\%) } & \multirow[t]{2}{*}{ PL (\%) } & \multirow[t]{2}{*}{$\mathrm{PI}(\%)$} \\
\hline Grain diam.(mm) & 0.002 & 0.01 & 0.02 & 0.03 & 0.075 & & & & \\
\hline Lamia & 15 & 39 & 89 & 96 & 100 & 2.52 & 57 & 32 & 25 \\
\hline Marl & 10 & 19 & 29 & 42 & 98 & 2.69 & 31 & 25 & 6 \\
\hline
\end{tabular}

Table 2: Compressibility characteristics

\begin{tabular}{|c|c|c|c|c|c|}
\hline Soil & $\mathrm{e}^{*} 100$ & $e^{*} 1000$ & $\mathrm{C}_{\mathrm{C}}^{*}$ & $\mathrm{C}_{\mathrm{s}}^{*}$ & $\mathrm{w}_{\mathrm{i}}(\%)$ \\
\hline \multirow[t]{9}{*}{ Lamia } & 1.096 & 0.715 & 0.38 & 0.09 & $1.41 \times L L$ \\
\hline & 1.135 & 0.744 & 0.39 & 0.06 & 1.32xLL \\
\hline & 1.030 & 0.704 & 0.33 & 0.09 & 1.25xLL \\
\hline & 0.970 & 0.670 & 0.30 & 0.09 & 1.15xLL \\
\hline & 0.820 & 0.576 & 0.25 & 0.10 & $0.81 \times L L$ \\
\hline & 0.611 & 0.373 & 0.24 & 0.09 & $0.55 \times L L$ \\
\hline & 1.000 & 0.625 & 0.38 & 0.06 & reconstituted: $1.28 x \mathrm{LL}$ \\
\hline & 1.050 & 0.640 & 0.41 & 0.06 & reconstituted: $1.28 x \mathrm{LL}$ \\
\hline & . & 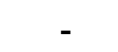 & 0.24 & 0.04 & intact \\
\hline \multirow[t]{8}{*}{ Marl } & 0.775 & 0.640 & 0.140 & - & 1.44xLL \\
\hline & 0.761 & 0.622 & 0.139 & 0.015 & 1.37xLL \\
\hline & 0.736 & 0.620 & 0.116 & - & 1.26xLL \\
\hline & 0.669 & 0.573 & 0.097 & - & 1.07xLL \\
\hline & 0.960 & 0.814 & 0.146 & - & 1.54xLL \\
\hline & 0.810 & 0.685 & 0.125 & - & 1.34xLL \\
\hline & 0.585 & 0.525 & 0.060 & 0.010 & $0.78 \times \mathrm{LL}$ \\
\hline & - & - & 0.23 & 0.009 & intact \\
\hline
\end{tabular}

$\mathrm{Cc}^{*}=$ intrinsic compression index, $\mathrm{Cs}^{*}=$ intrinsic swelling index 
Table 3: Lamia specimen characteristics

\begin{tabular}{ccccc}
\hline $\mathrm{p}_{0}(\mathrm{kPa})$ & $\mathrm{e}_{\mathrm{i}}$ & $\mathrm{e}_{0}$ & OCR & Undrained/Drained U/D \\
\hline 100 & 1.004 & 0.965 & 1 & U_reconstituted \\
200 & 1.068 & 0.958 & 1 & U_reconstituted \\
300 & 1.031 & 0.801 & 1 & U_reconstituted \\
400 & 1.068 & 0.818 & 1 & U_reconstituted \\
200 & 1.072 & 0.832 & 2 & U_reconstituted \\
100 & 1.070 & 0.843 & 4 & U_reconstituted \\
200 & 0.857 & 0.721 & 2 & D_reconstituted \\
100 & 0.809 & 0.723 & 4 & D_reconstituted \\
50 & 0.936 & 0.745 & 8 & D_reconstituted \\
110 & $0.756^{*}$ & 0.754 & - & U_intact \\
145 & “ & 0.751 & - & U_intact \\
200 & “ & 0.740 & - & U_intact \\
280 & “ & 0.730 & - & U_intact \\
500 & 0.709 & - & U_intact \\
\hline
\end{tabular}

Note: initial states after reconsolidation in the triaxial $\mathrm{p}_{0}, \mathrm{e}_{0}$; initial states before reconsolidation in the triaxial $e_{i}$, where $e_{i}=0.756^{*}=w_{i}(\%) \times G_{s}=0.30 \times 2.52$

Table 4: Marl specimen characteristics

\begin{tabular}{cccccc}
\hline No & $\mathrm{p}_{0}(\mathrm{kPa})$ & $\mathrm{e}_{\mathrm{i}}$ & $\mathrm{e}_{0}$ & OCR & Undrained/Drained U/D \\
\hline 1 & 94 & 0.740 & 0.671 & 1 & U_reconstituted \\
2 & 153 & 0.699 & 0.587 & 2 & U_reconstituted \\
3 & 203 & 0.710 & 0.622 & 1 & U_reconstituted \\
4 & 302 & 0.718 & 0.605 & 1 & U_reconstituted \\
5 & 301 & 0.718 & 0.600 & 1 & U_reconstituted \\
6 & 305 & 0.721 & 0.618 & 1 & U_reconstituted \\
7 & 298 & 0.682 & 0.600 & 1 & U_reconstituted \\
12 & 402 & 0.699 & 0.600 & 1 & U_reconstituted \\
13 & 391 & 0.689 & 0.629 & 1 & U_reconstituted \\
14 & 595 & 0.675 & 0.626 & 1 & Urreconstituted \\
8 & 98 & 0.705 & 0.689 & 3 & p'=ct_reconstituted \\
15 & 398 & 0.686 & 0.637 & 1 & p'ct_reconstituted $^{\prime}=$ ctrreconstituted \\
9 & 209 & 0.653 & 0.634 & 1 & D_reconstituted \\
11 & 402 & 0.699 & 0.627 & 1 & D_reconstituted \\
16 & 298 & 0.704 & 0.637 & 1 & D_reconstited \\
17 & 299 & 0.659 & 0.635 & 1 & D_reconstituted \\
18 & 503 & 0.656 & 0.633 & 1 & D_reconstituted \\
- & 575 & 0.671 & 0.651 & - & p'=ct_intact \\
- & 430 & 0.670 & 0.652 & - & p'=ct_intact \\
- & 400 & 0.677 & 0.656 & - & p'=ct_intact \\
- & 240 & 0.665 & 0.655 & - & p'=ct_intact \\
\hline
\end{tabular}

Note: initial states after reconsolidation in the triaxial $p_{0}, e_{0}$; initial states before reconsolidation in the triaxial $e_{i}$; intact specimens were anisotropically consolidated 


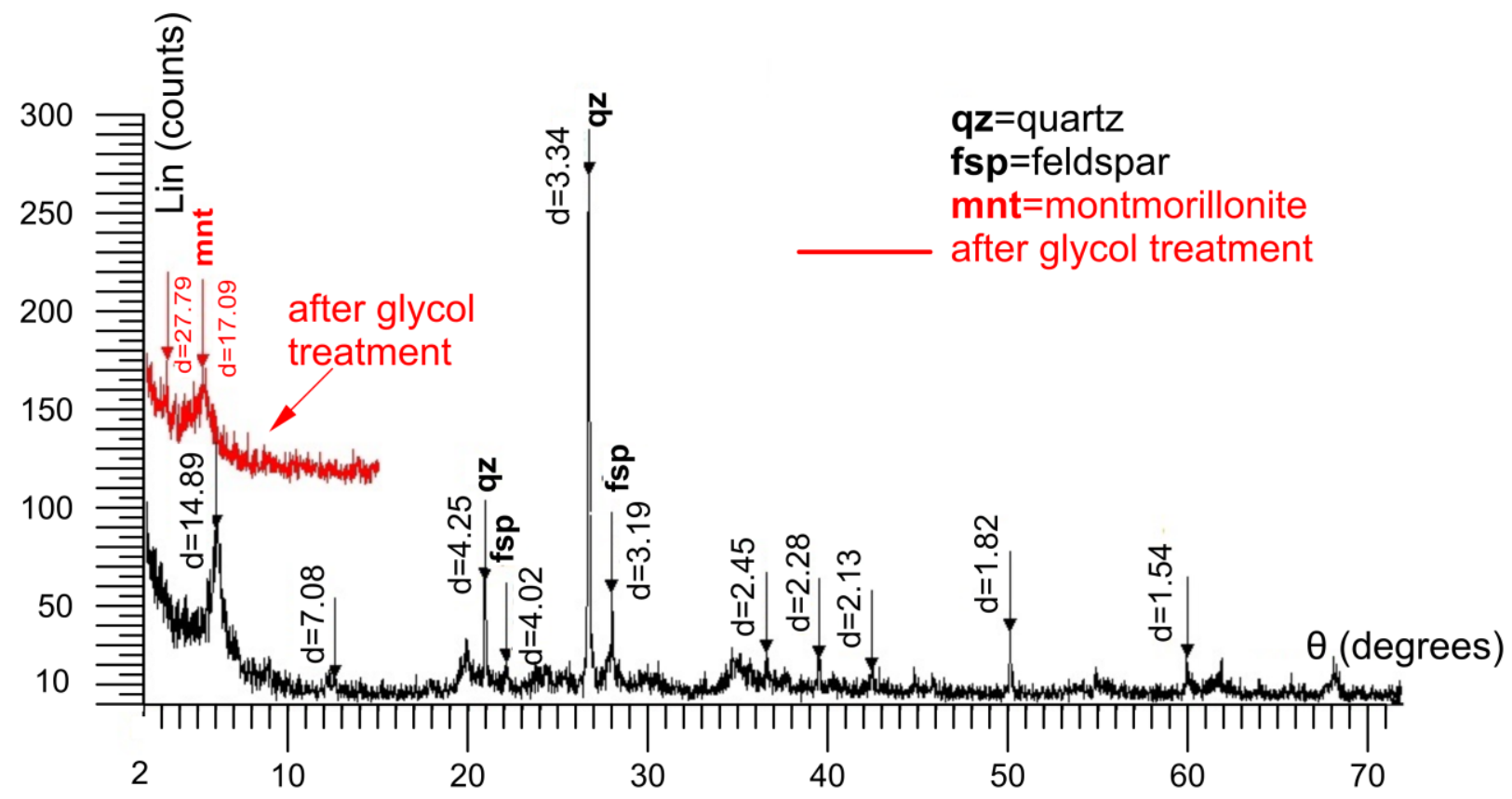

Fig. 1. Results from XRD analysis 


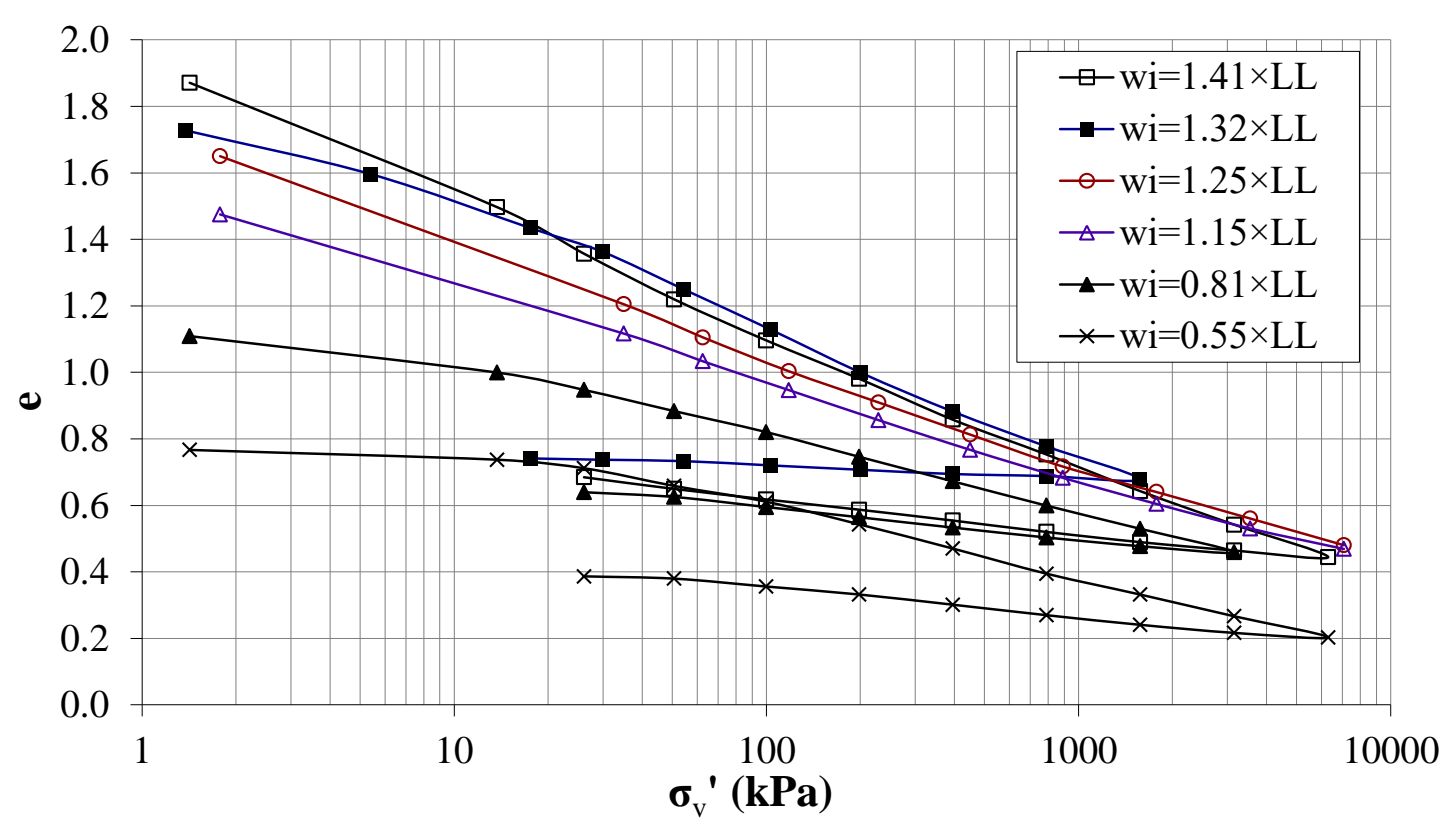

(a)

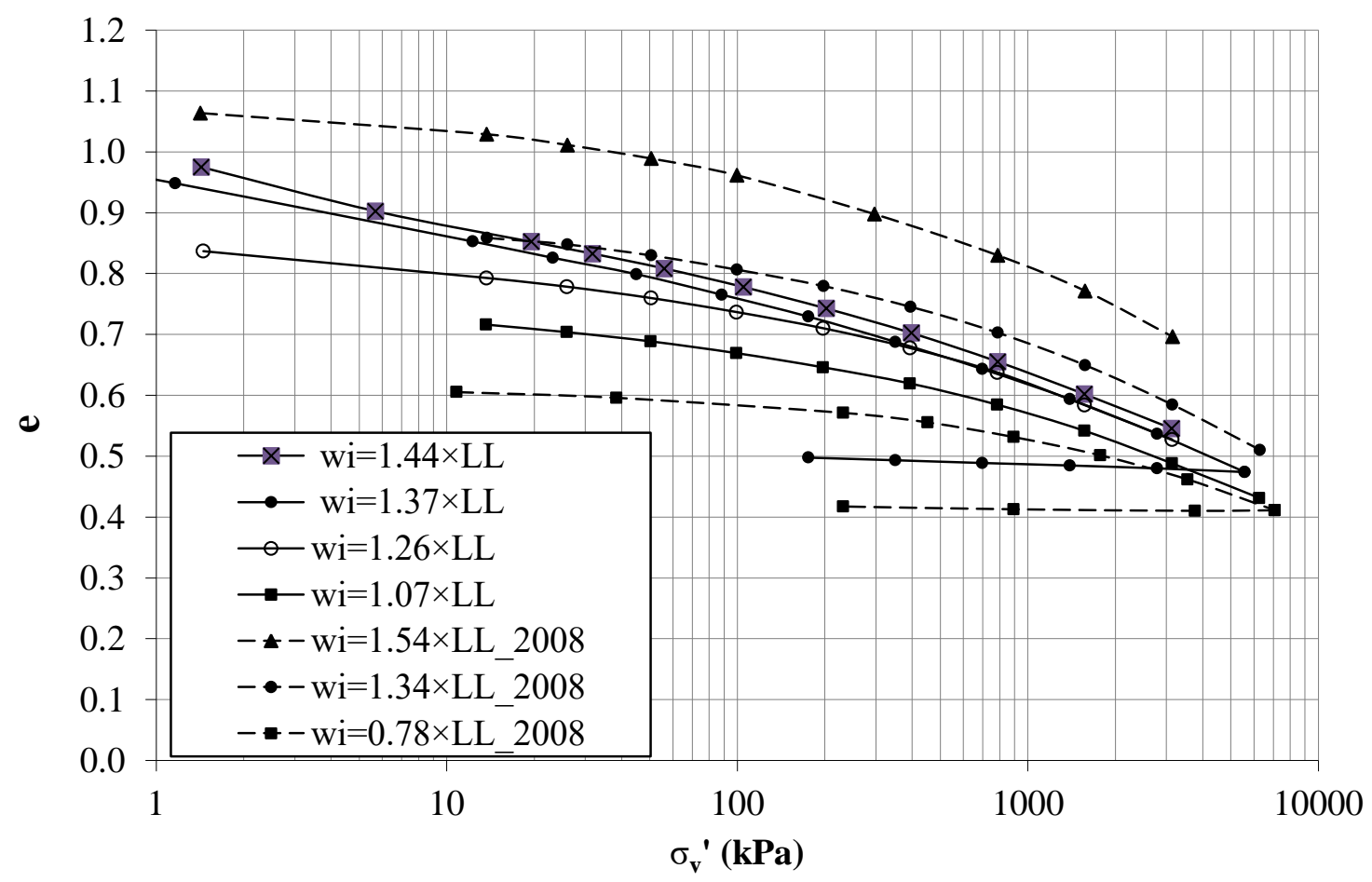

(b)

Fig. 2. Normal compression curves, e vs $\log \sigma v^{\prime}$, for materials reconstituted from slurry in the standard oedometer at moisture contents of between 1.54-0.78 times the liquid limit of the natural materials (a) Lamia; (b) Marl 


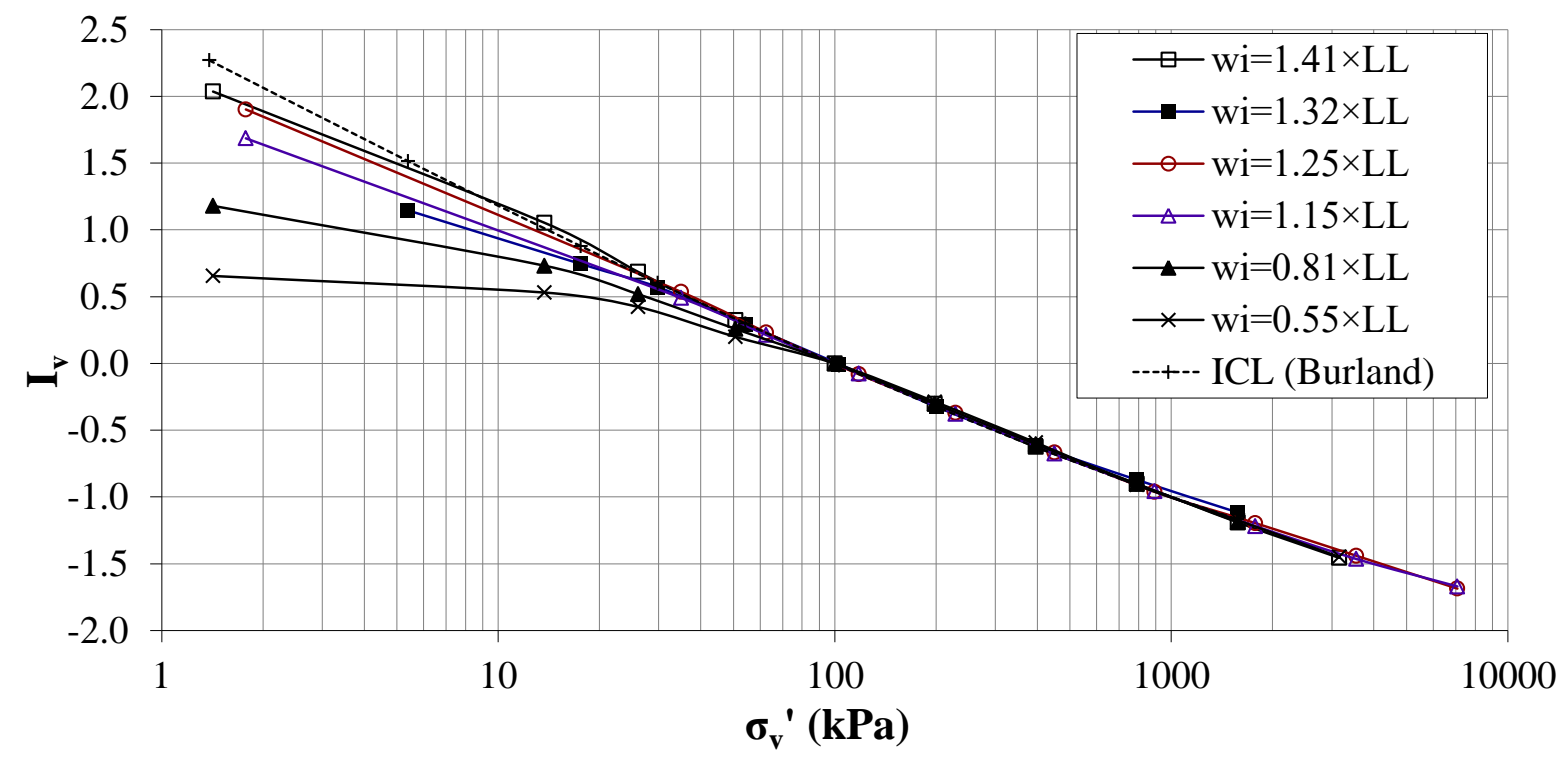

(a)

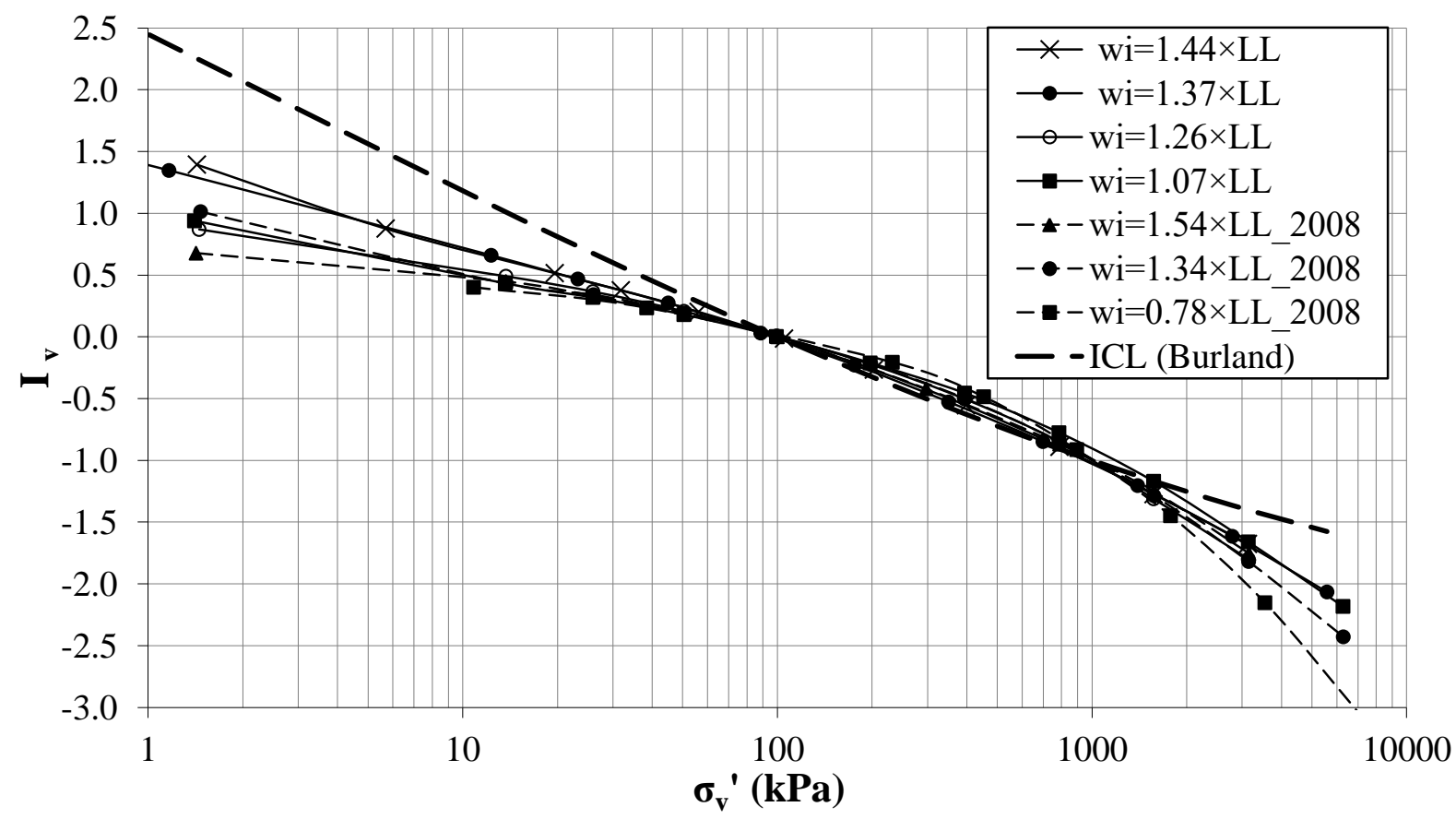

(b)

Fig. 3: Normal compression curves, $I_{v} v s \log \sigma_{v}{ }^{\prime}$, for materials reconstituted from slurry in the standard oedometer (a) Lamia; (b) Marl 


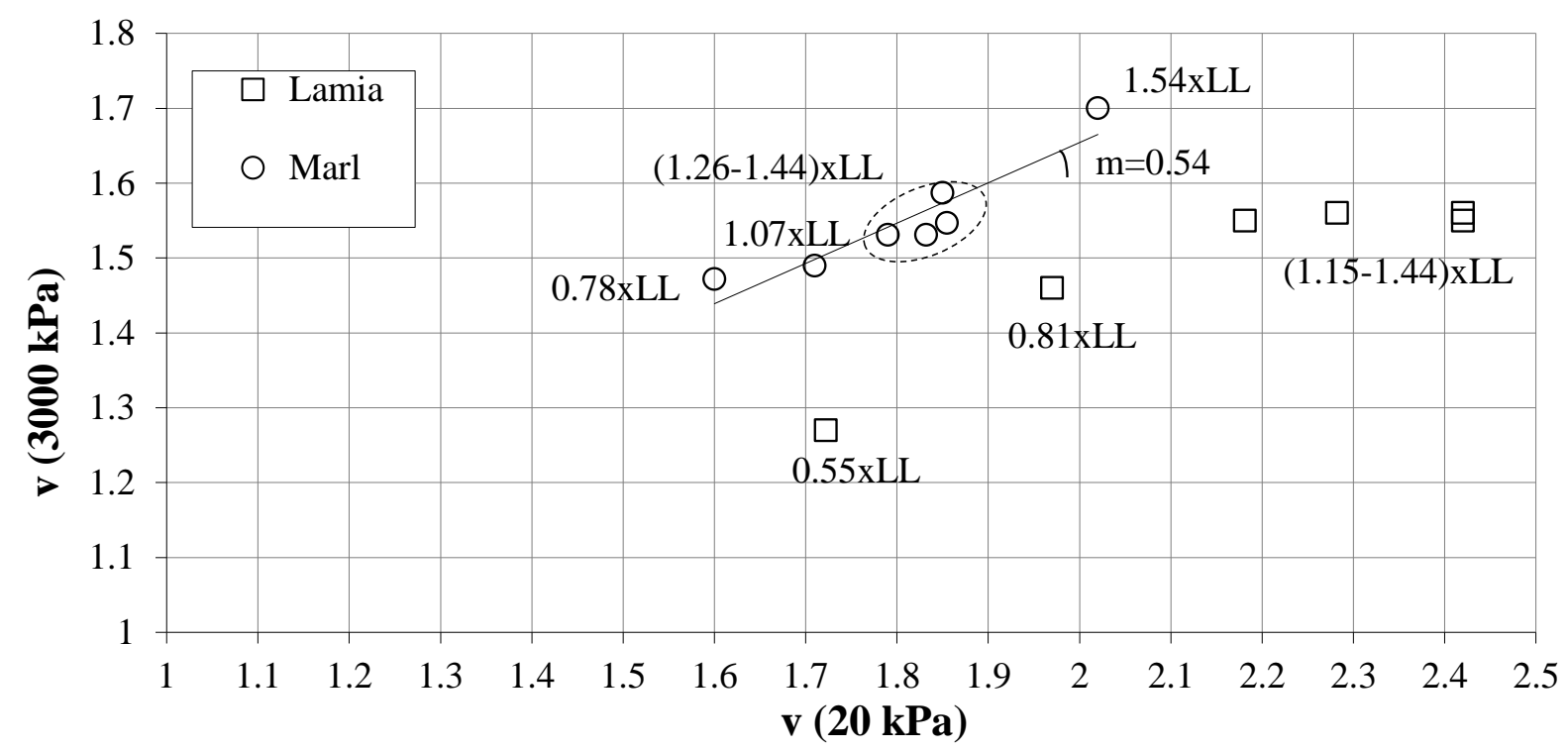

Fig.4: Quantification of the convergence of reconstituted samples; calculation of the parameter $\mathrm{m}$ 


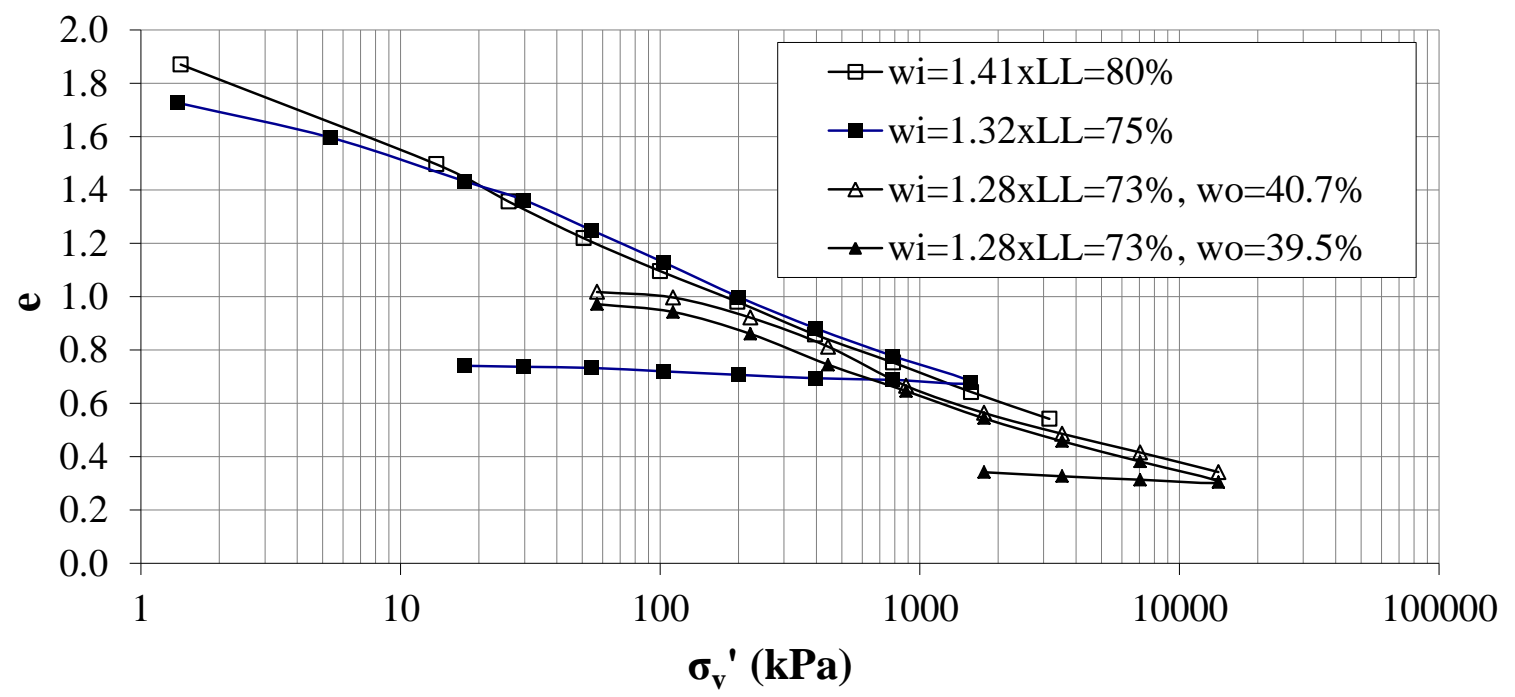

(a)

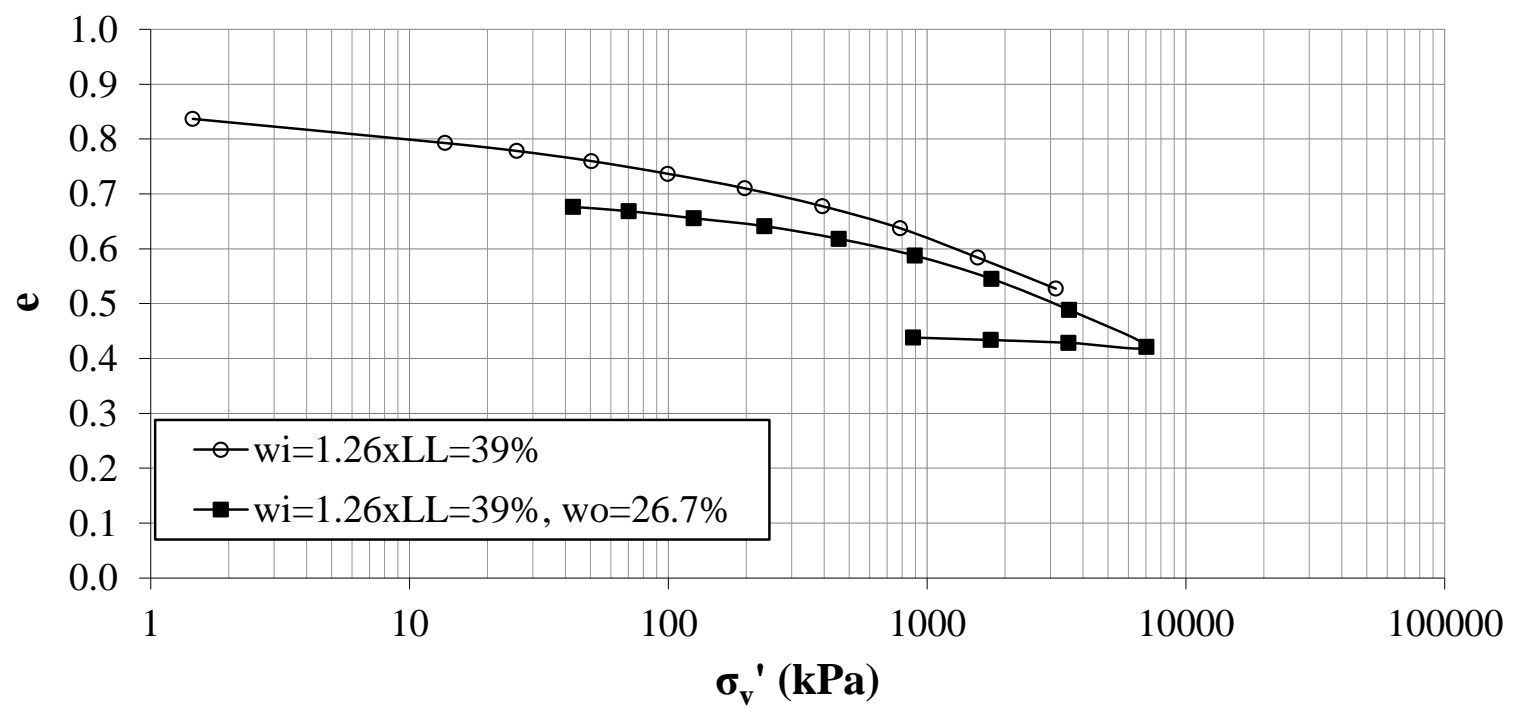

(b)

Fig. 5. Oedometer compression curves for (a) Lamia specimens 'reconstituted' in the consolidometer $\left(\mathrm{w}_{\mathrm{i}}=73 \%, \mathrm{w}_{0}=40.7 \% \& 39.5 \%\right)$ and material reconstituted from slurry in a standard oedometer $\left(\mathrm{w}_{\mathrm{i}}=75 \%\right.$ \& 80\%); (b) Marl specimens 'reconstituted' in the consolidometer $\left(\mathrm{w}_{\mathrm{i}}=39 \%, \mathrm{w}_{0}=26.7 \%\right)$ and material reconstituted from slurry in a standard oedometer $\left(\mathrm{w}_{\mathrm{i}}=39 \%\right)$ 


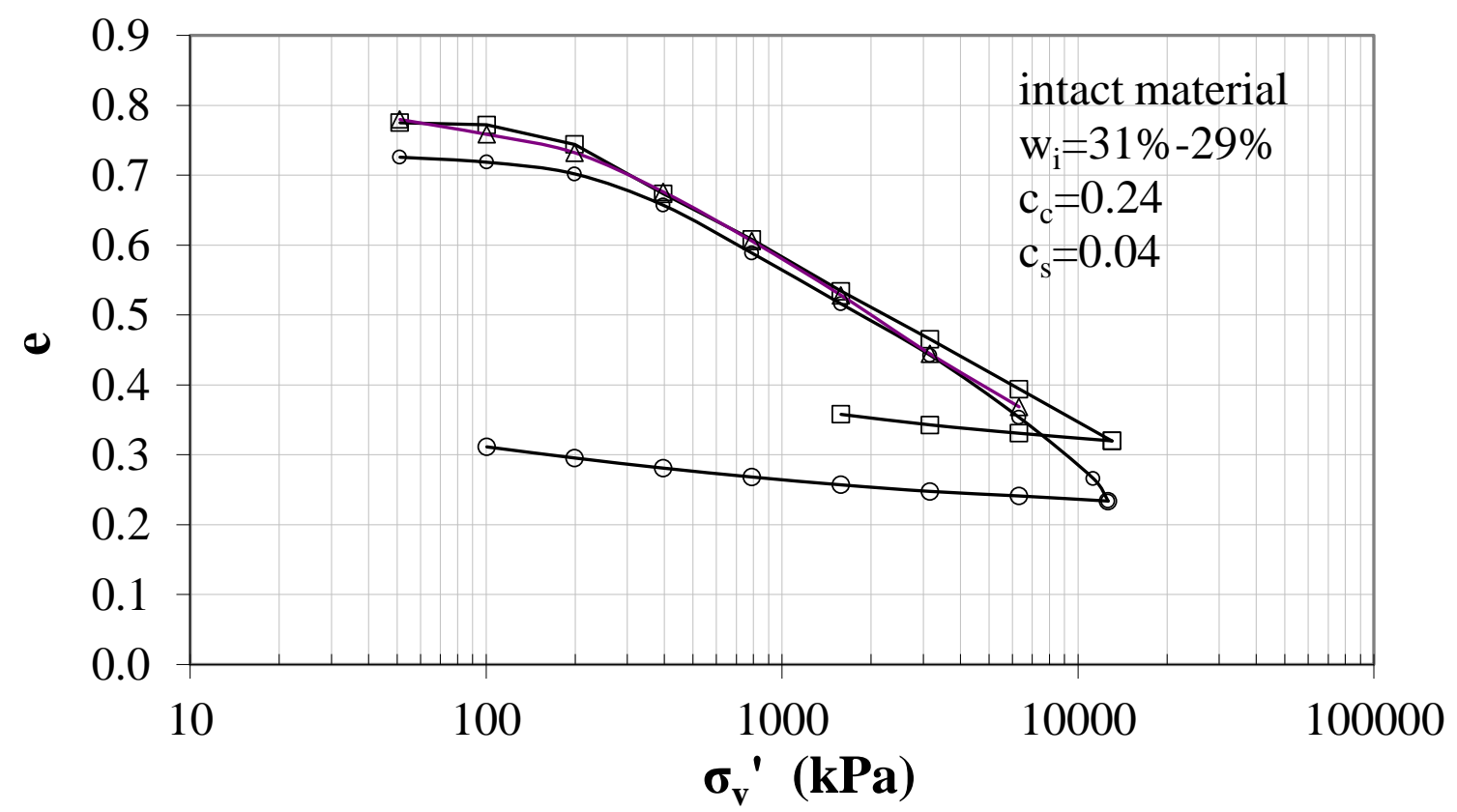

(a)

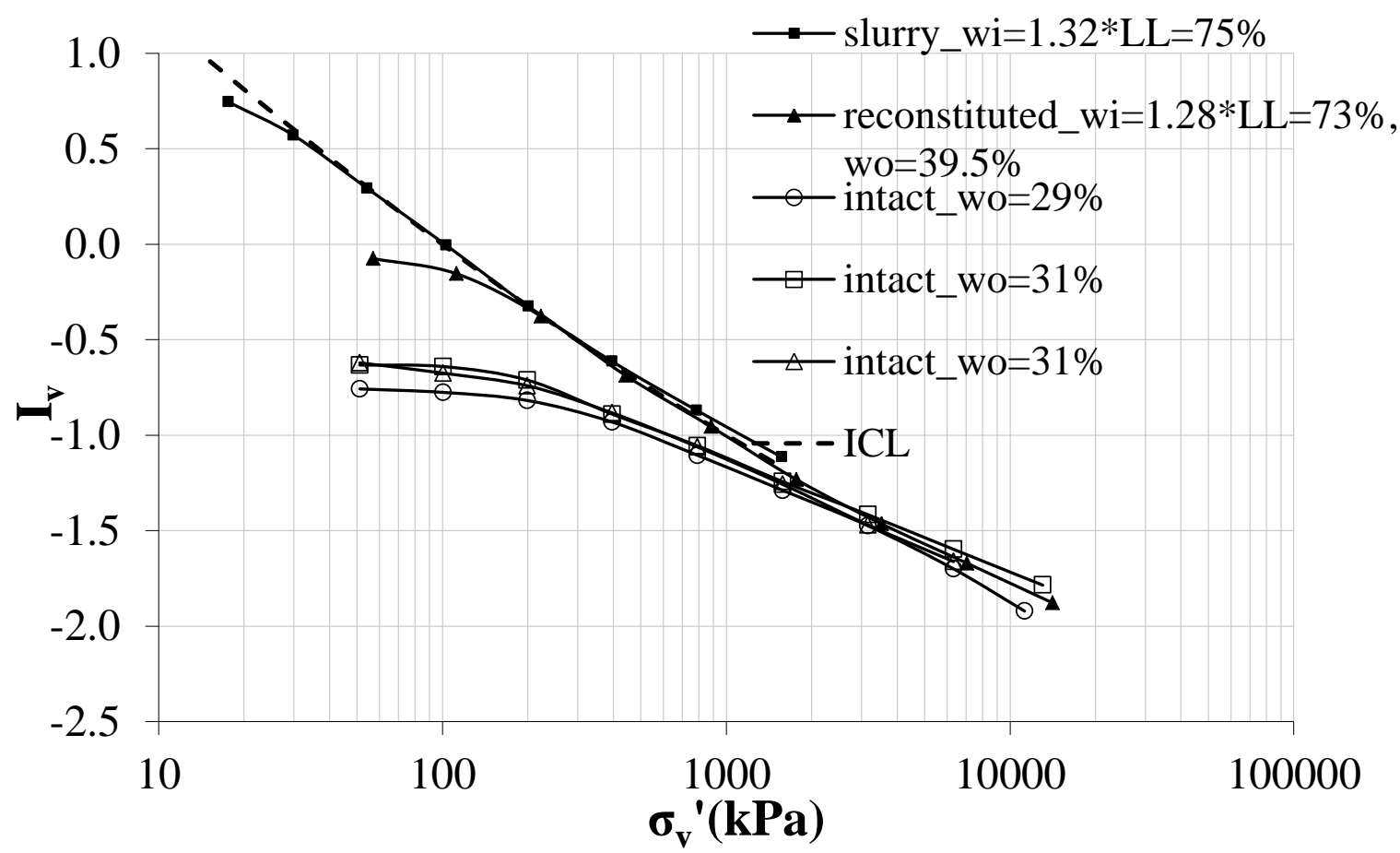

(b)

Fig. 6. Intact Lamia: (a) e vs $\log \sigma_{v}{ }^{\prime}$; (b) $I_{v} v s \log \sigma_{v}{ }^{\prime}$ 


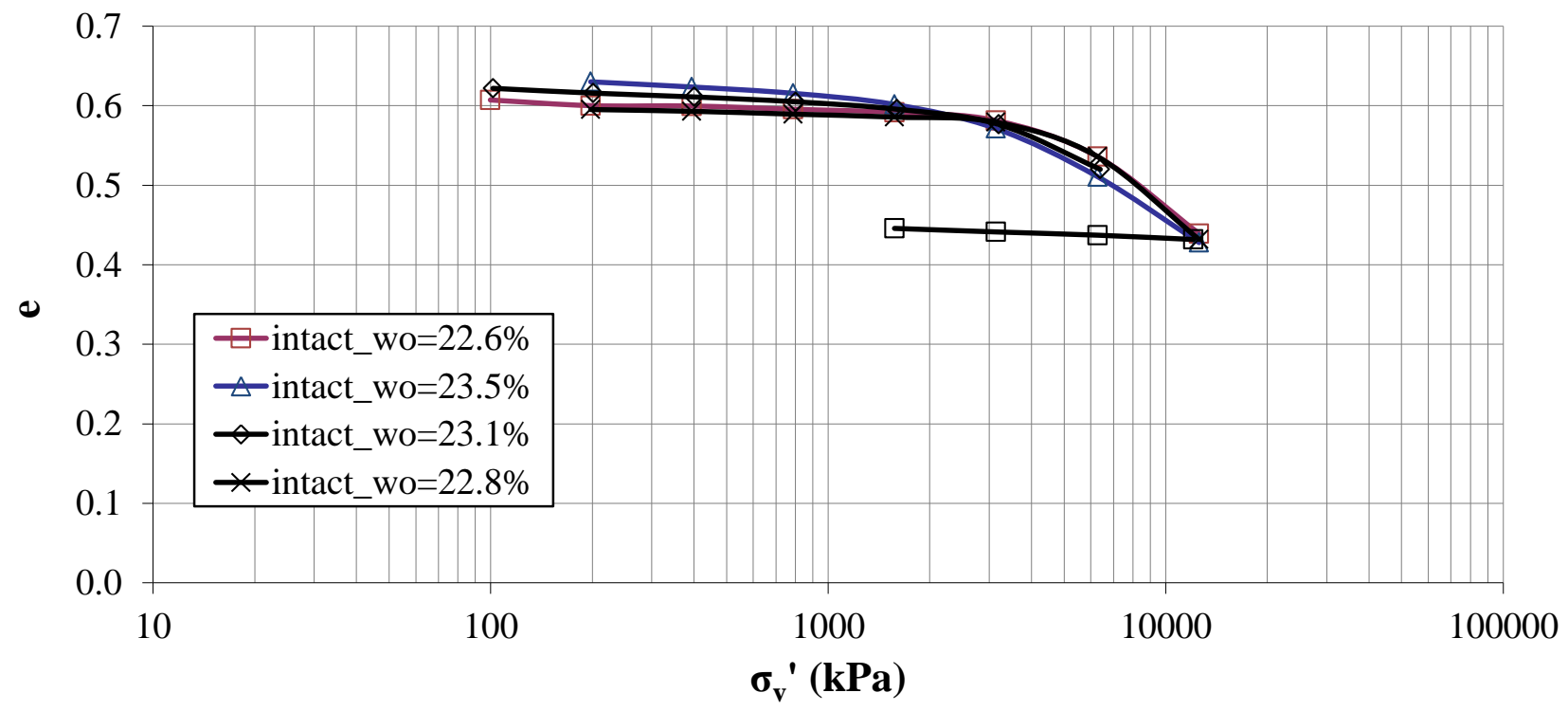

(a)

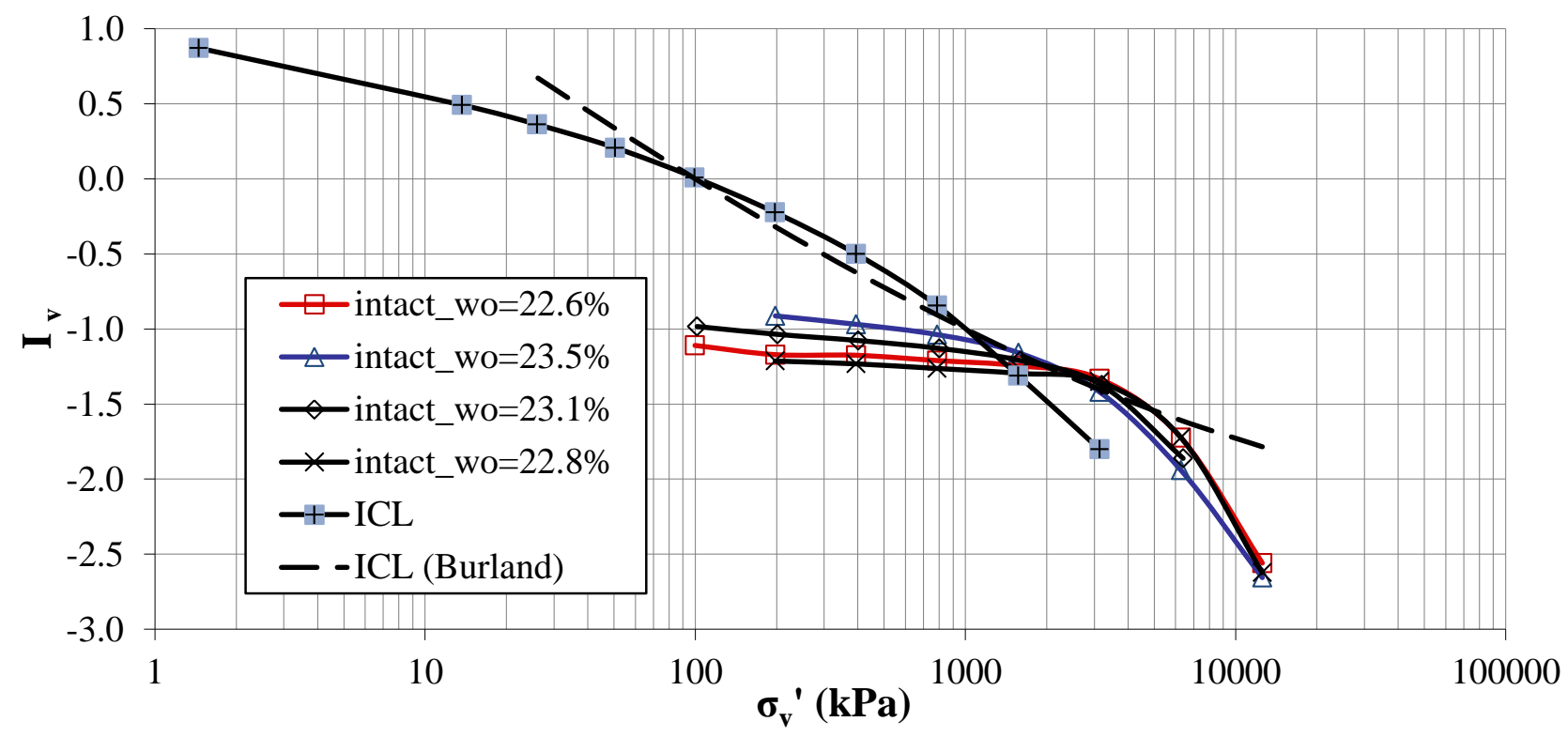

(b)

Fig. 7. Intact Marl: (a) e vs $\log \sigma_{v}^{\prime}$; (b) $I_{v} v s \quad \log \sigma_{v}{ }^{\prime}$ 


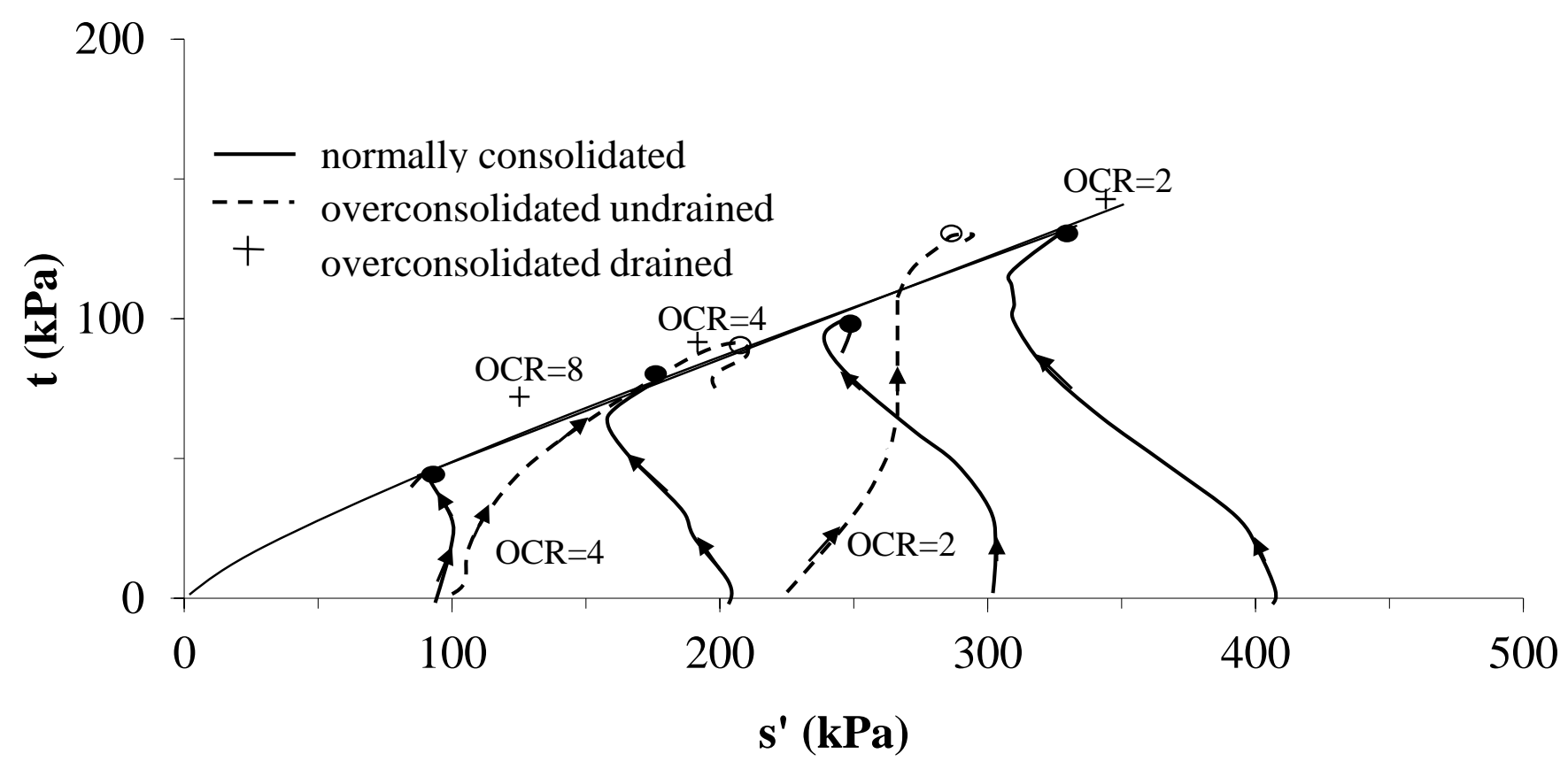

(a) 


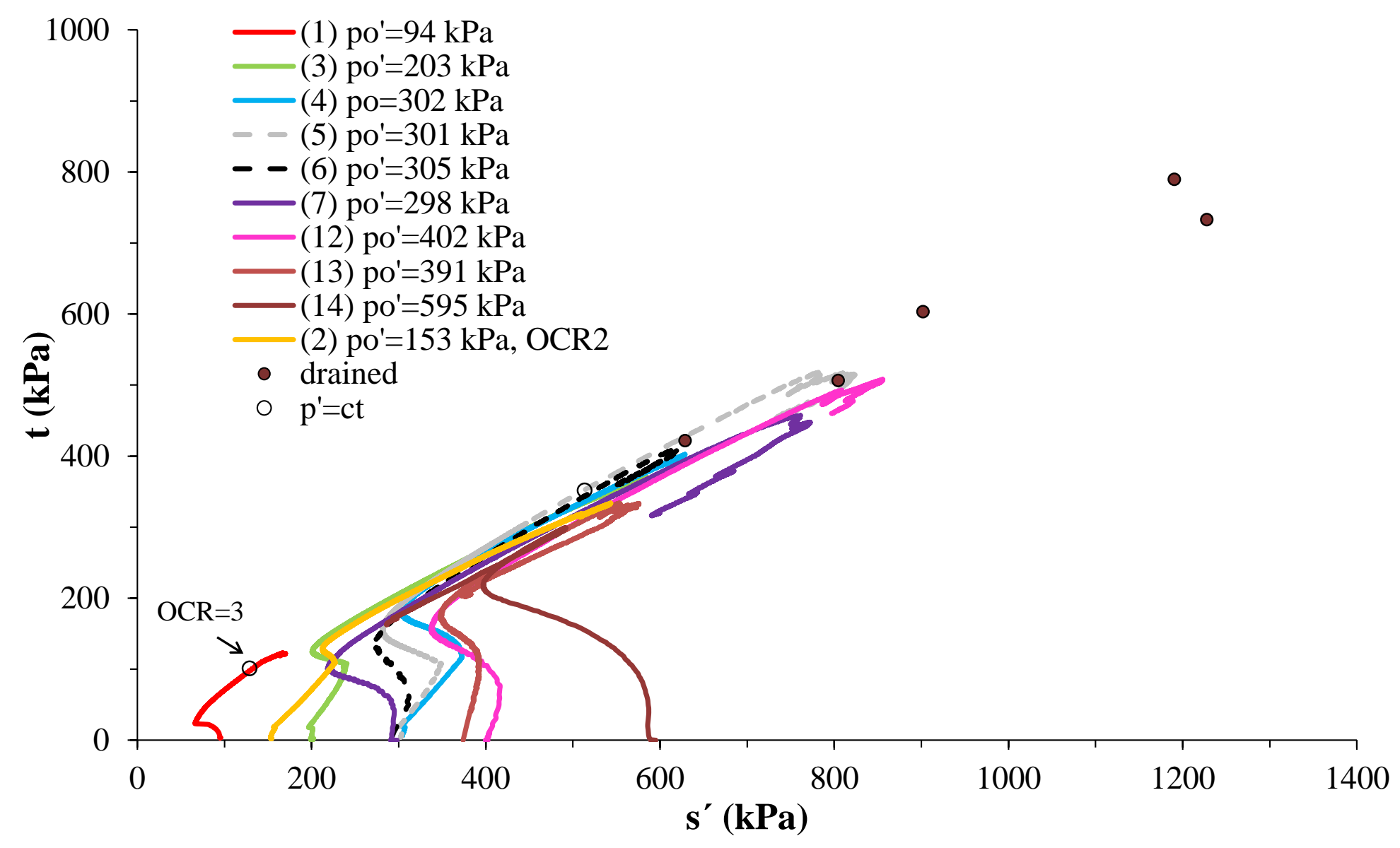

(b)

Fig. 8. Undrained effective stress paths for a) reconstituted Lamia specimens; b) reconstituted Marl specimens 


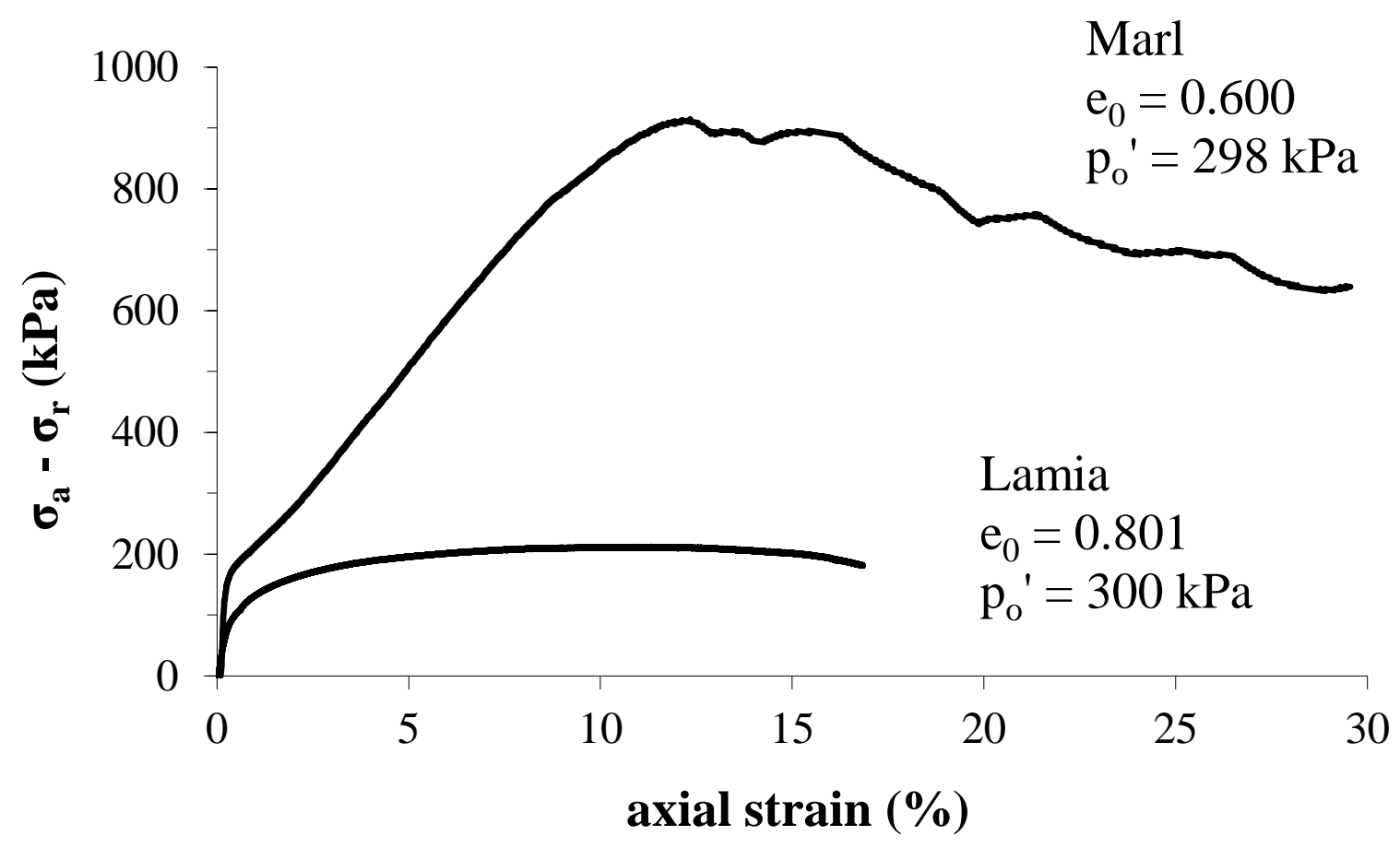

(a)

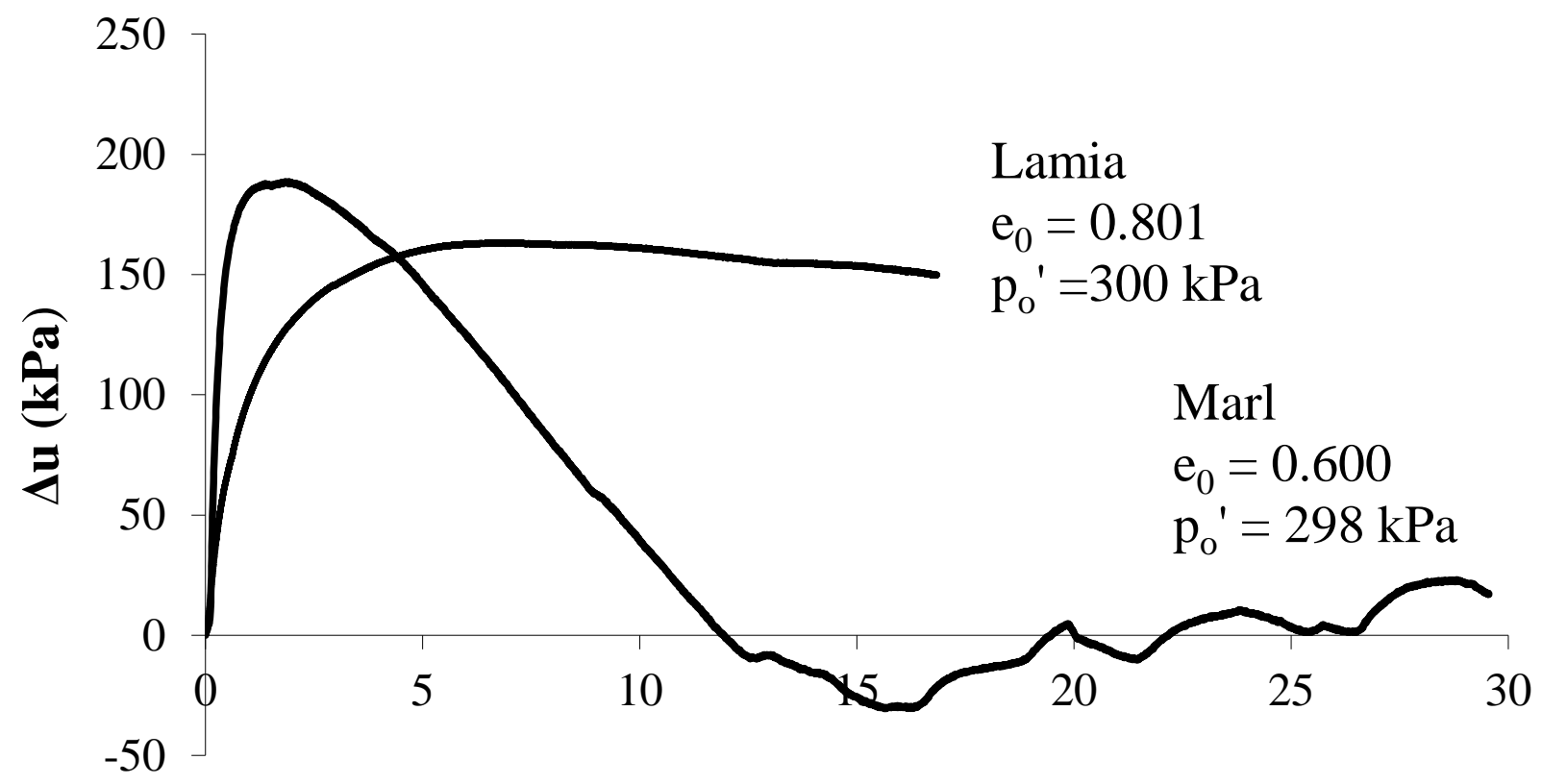

axial strain (\%)

(b)

Fig. 9. Typical reconstituted Lamia and Marl specimens: undrained tests (a) stressstrain curves; (b) excess pore water pressure against axial strain curves 


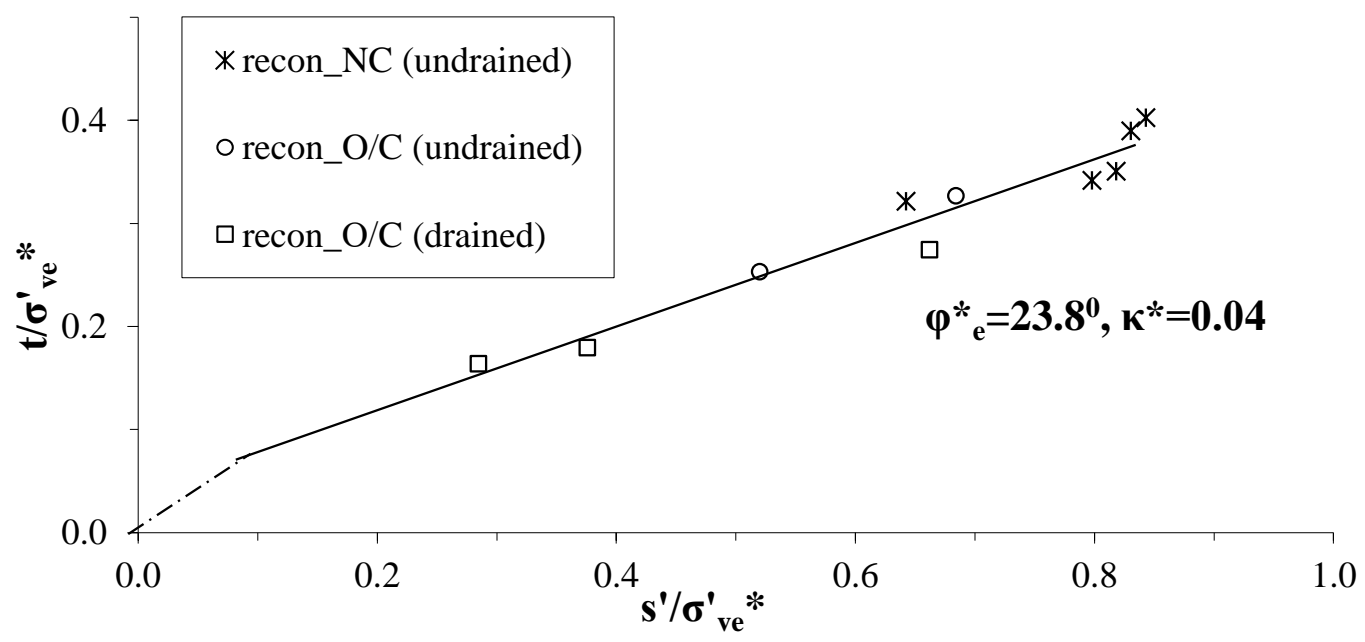

(a)

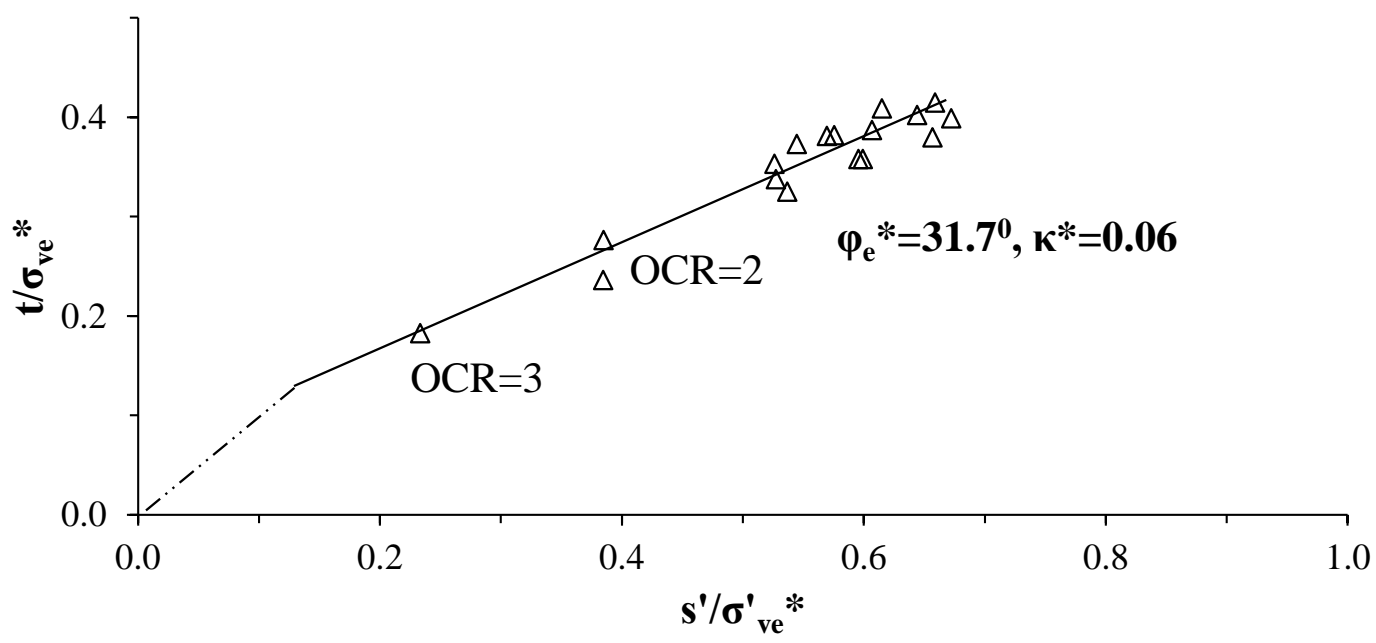

(b)

Fig. 10. Intrinsic Hvorslev strength envelope: (a) Lamia; (b) Marl 


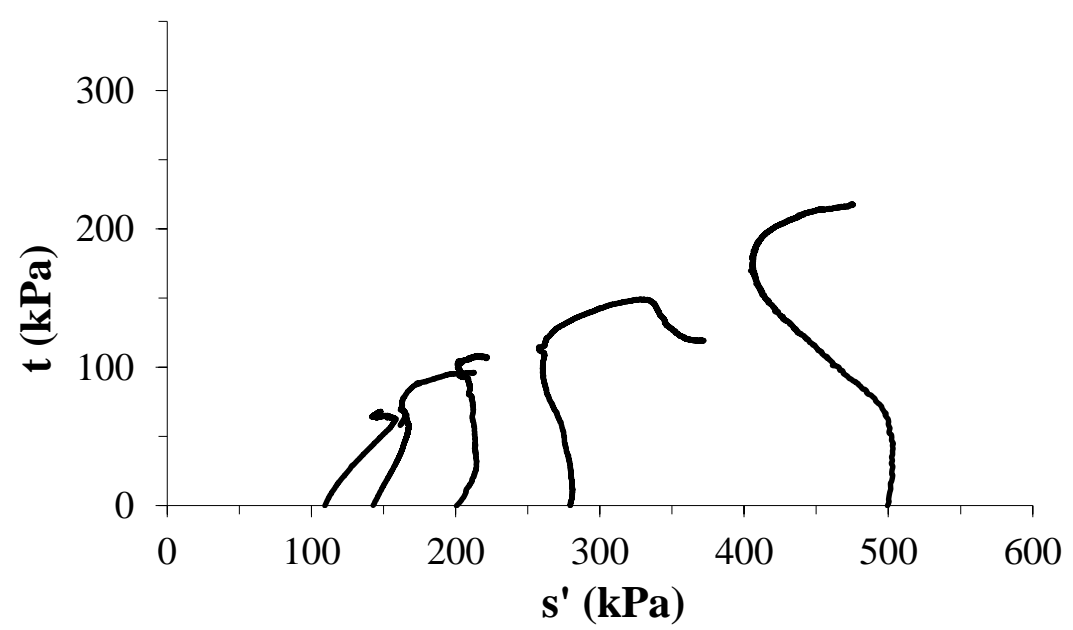

(a)

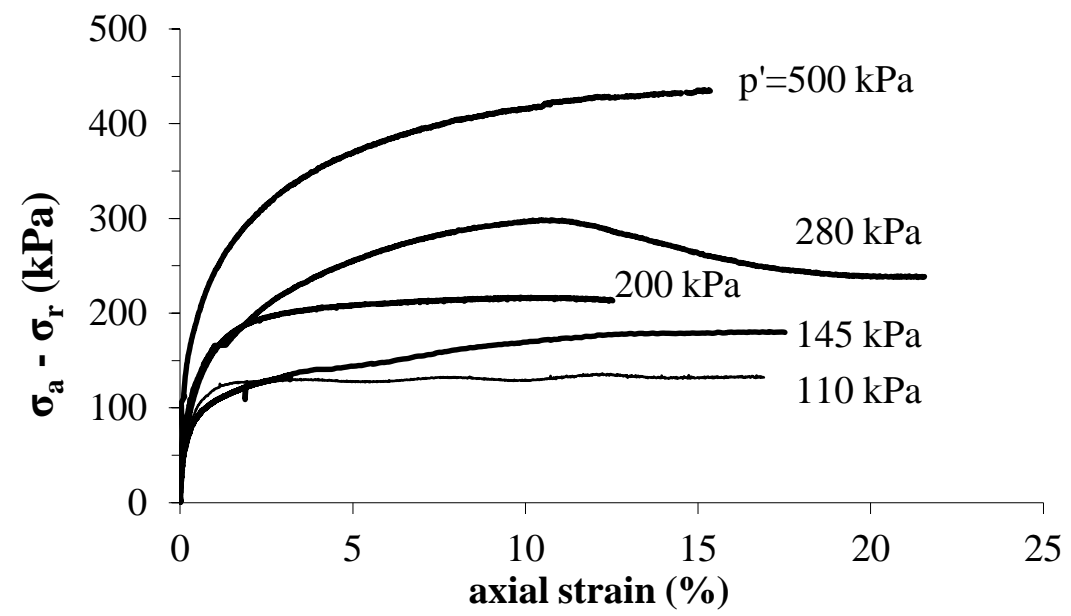

(b)

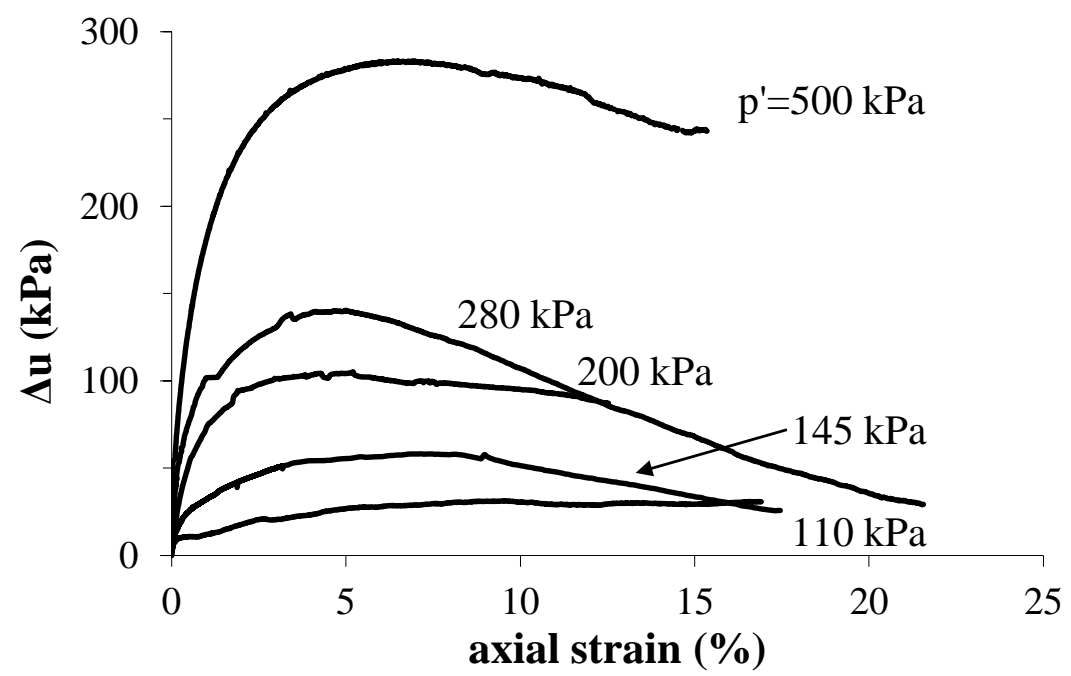

(c)

Fig. 11. Undrained tests on intact Lamia: (a) stress paths; (b) stressstrain curves; (c) excess pore water pressure against axial strain curves 


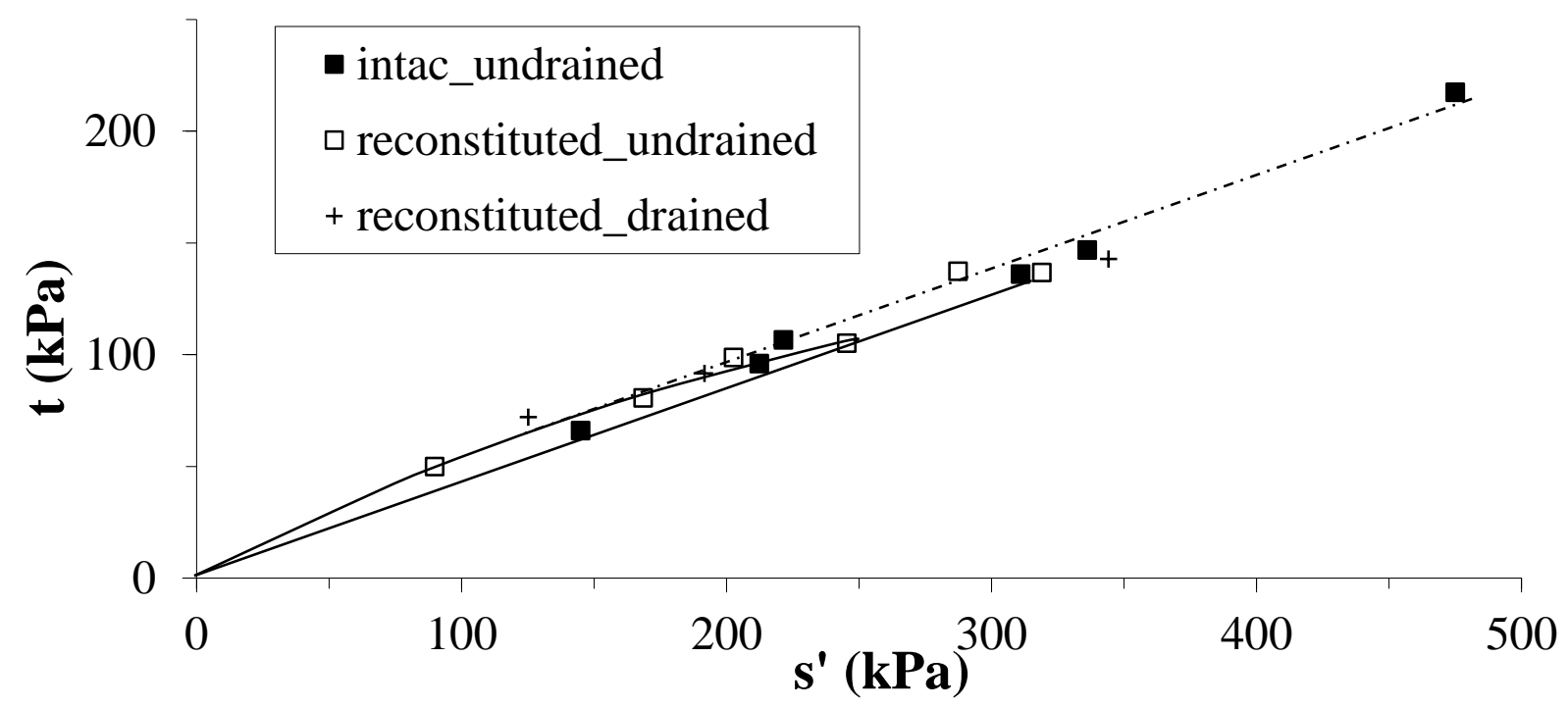

Fig.12. Peak strengths: intact and reconstituted Lamia specimens 


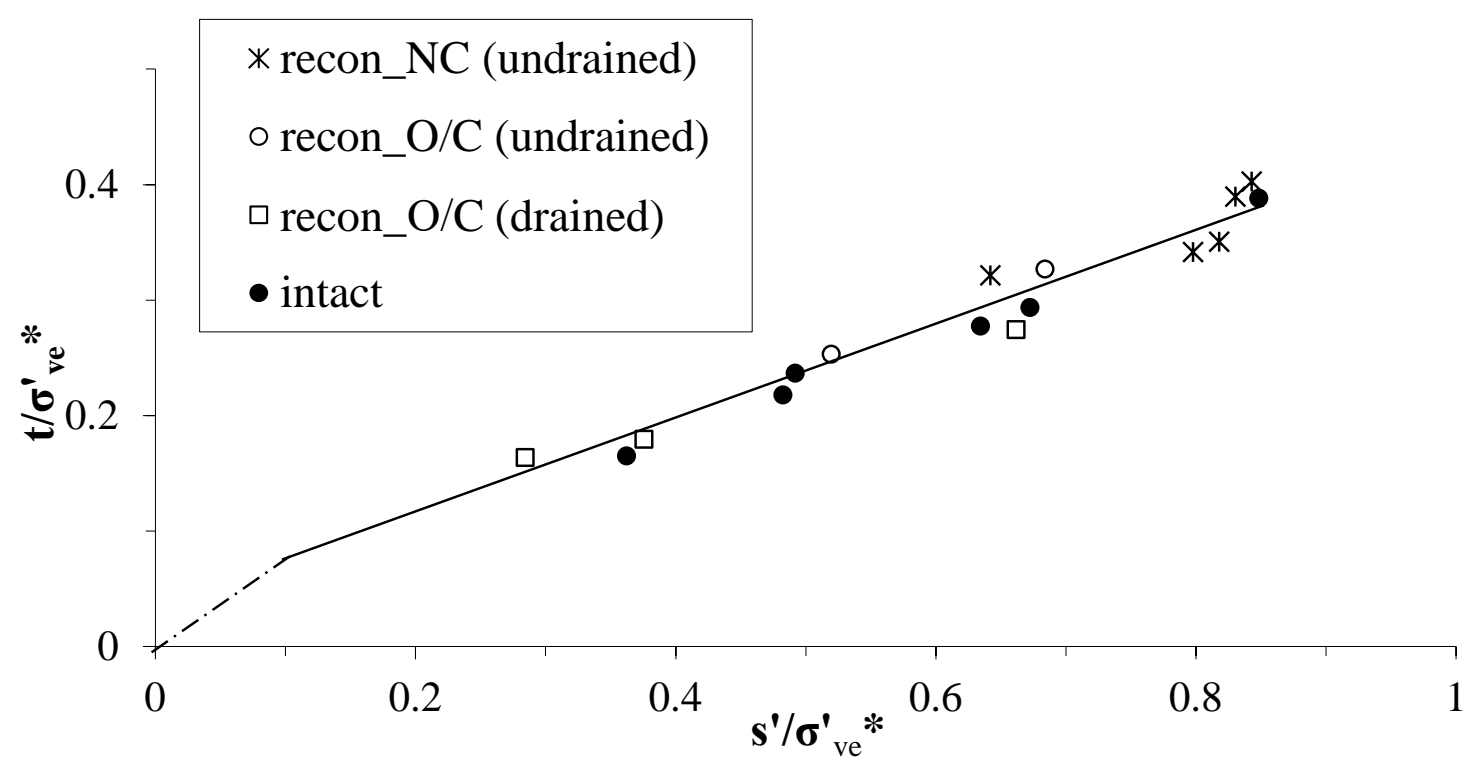

Fig. 13. Comparison of intact and intrinsic Hvorslev strength envelopes for Lamia 


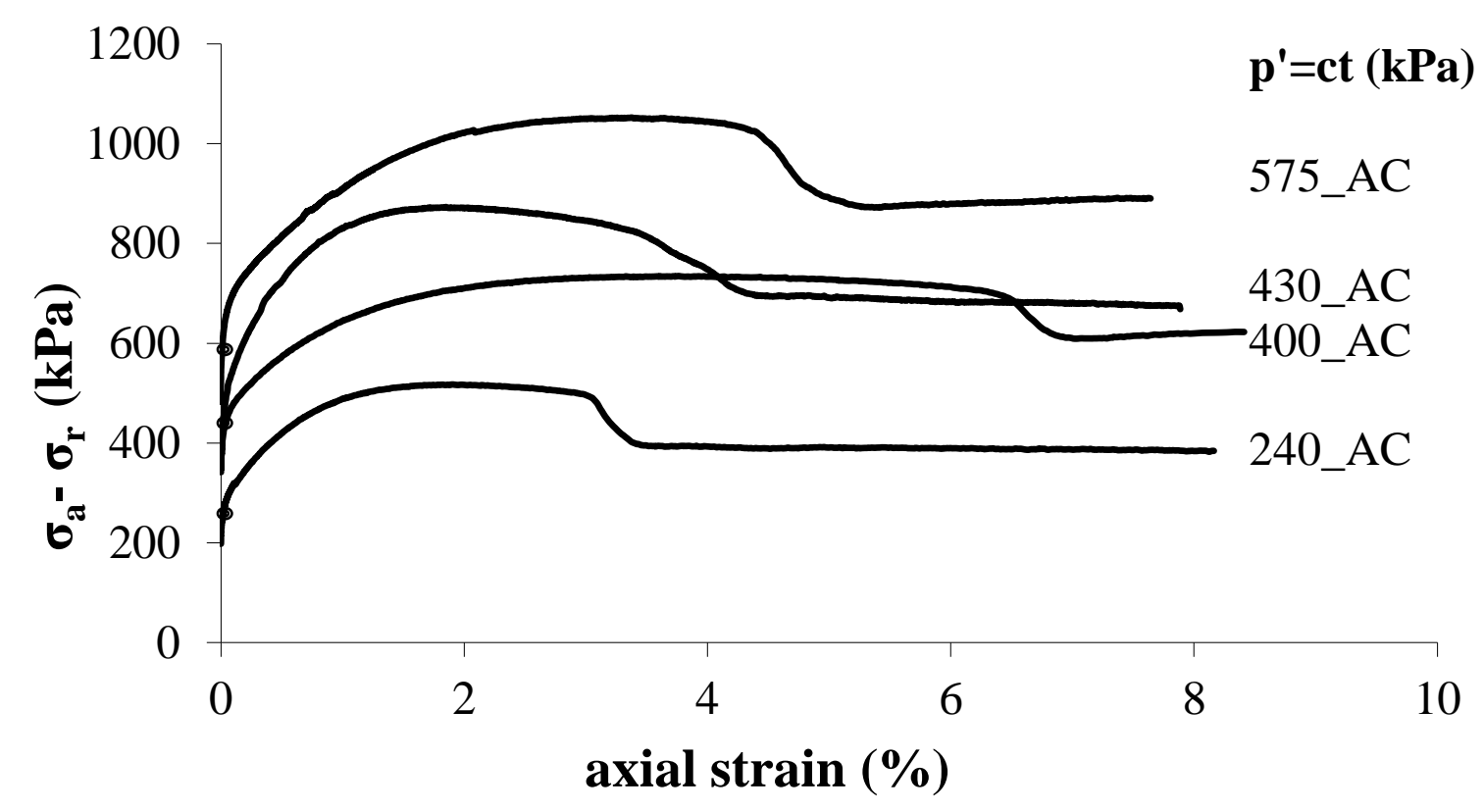

(a)

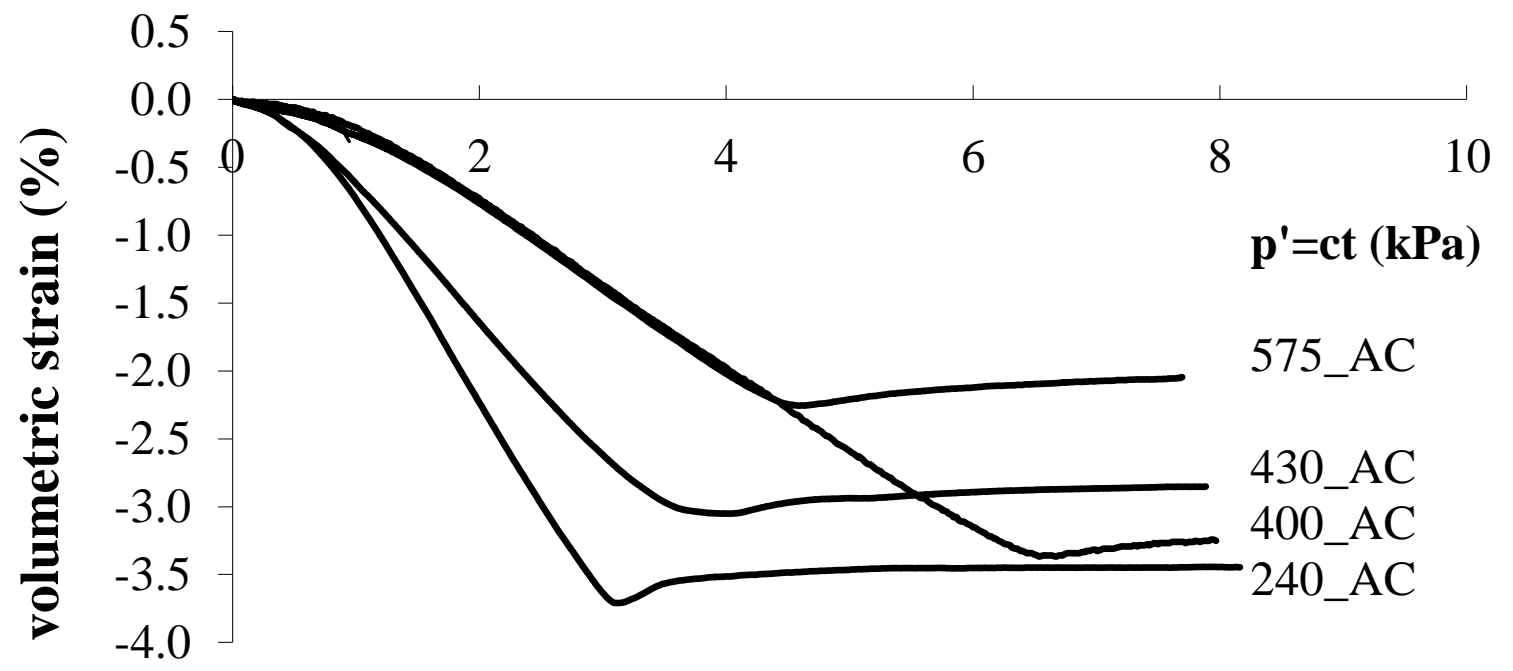

axial strain (\%)

(b)

Fig. 14. Constant p' tests on intact Marl (a) stress-strain curves; (b) volumetric against axial strain curves 


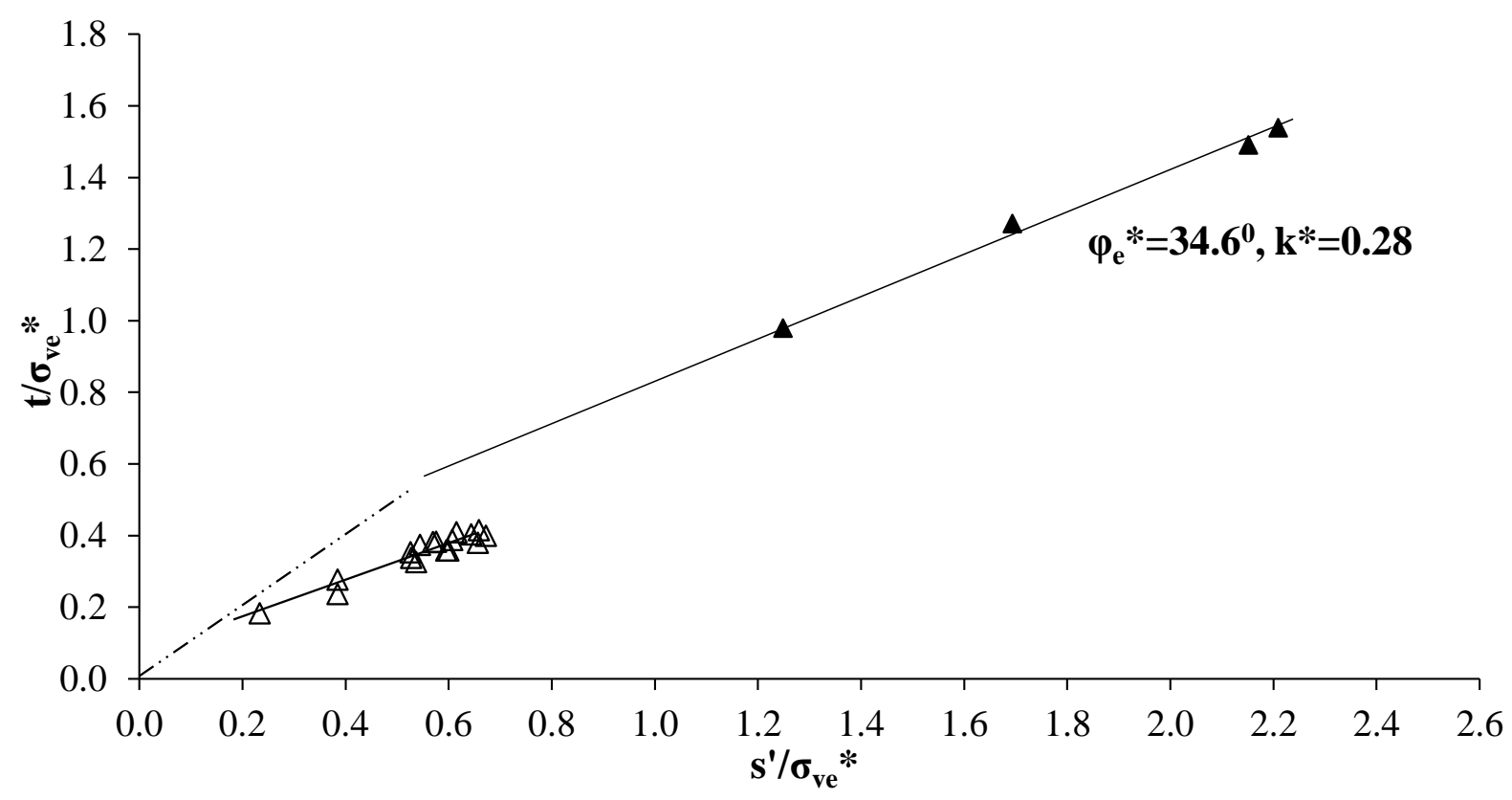

Fig. 15. Comparison of intact and intrinsic Hvorslev strength envelopes for Marl 


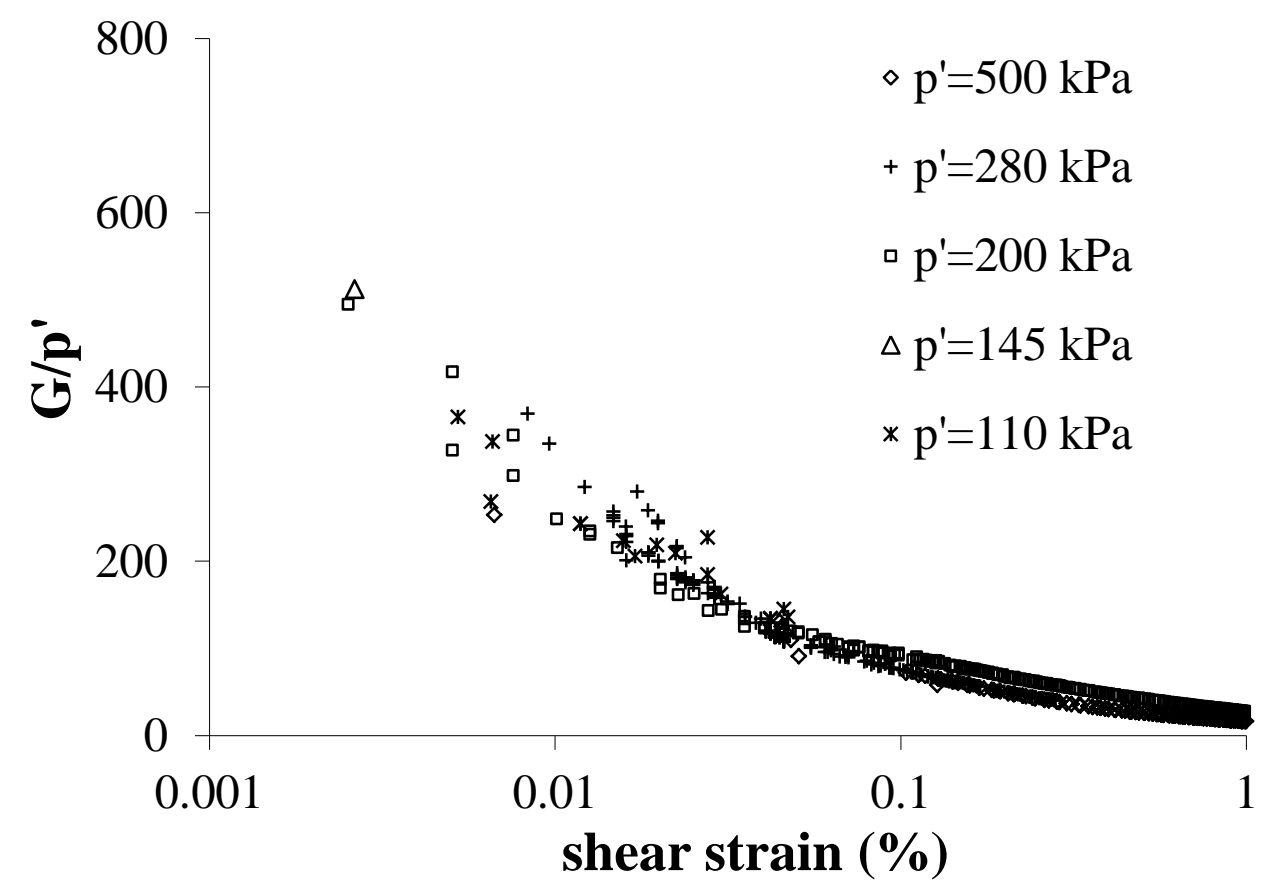

(a)

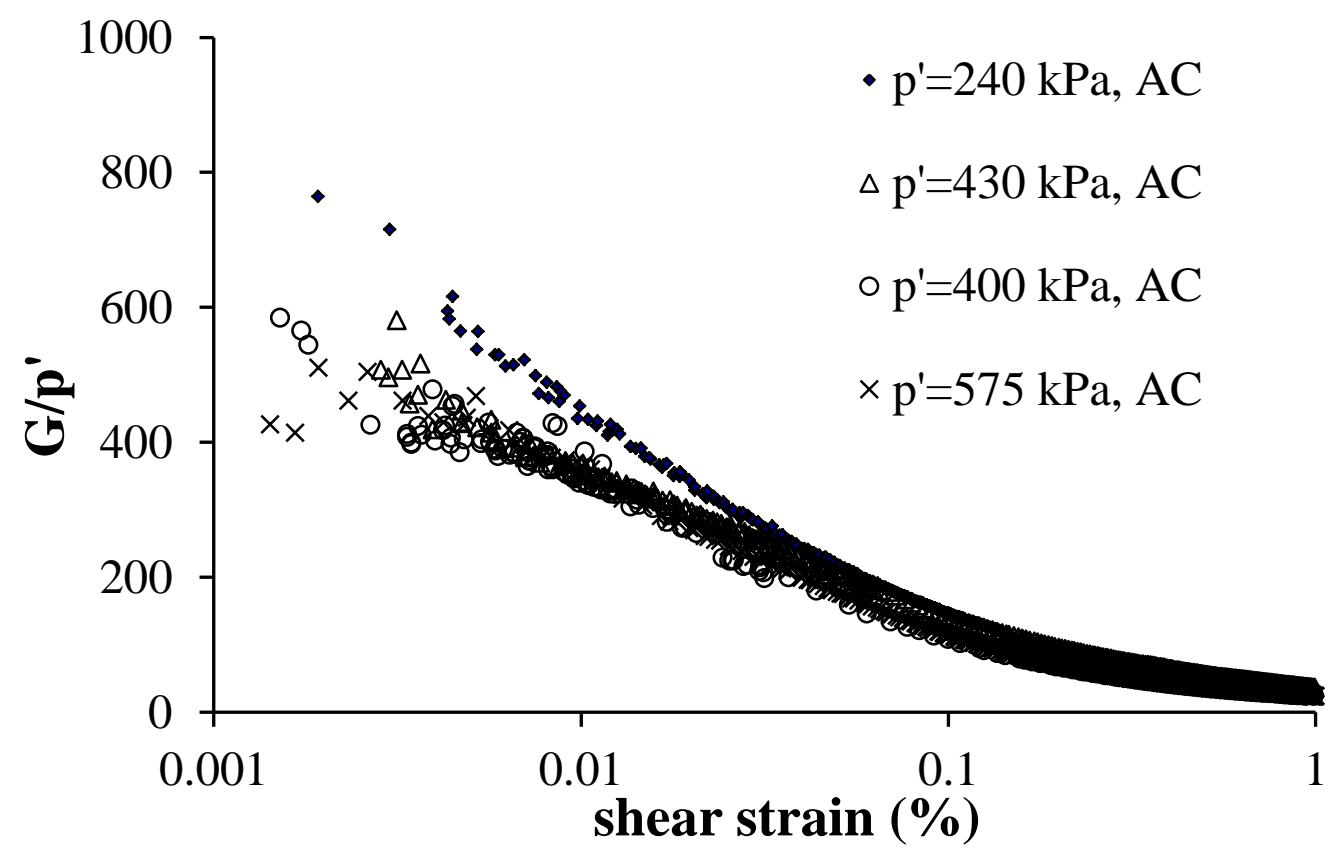

(b)

Fig. 16. Variation of normalized shear modulus with strain: (a) Lamia; (b) Marl 


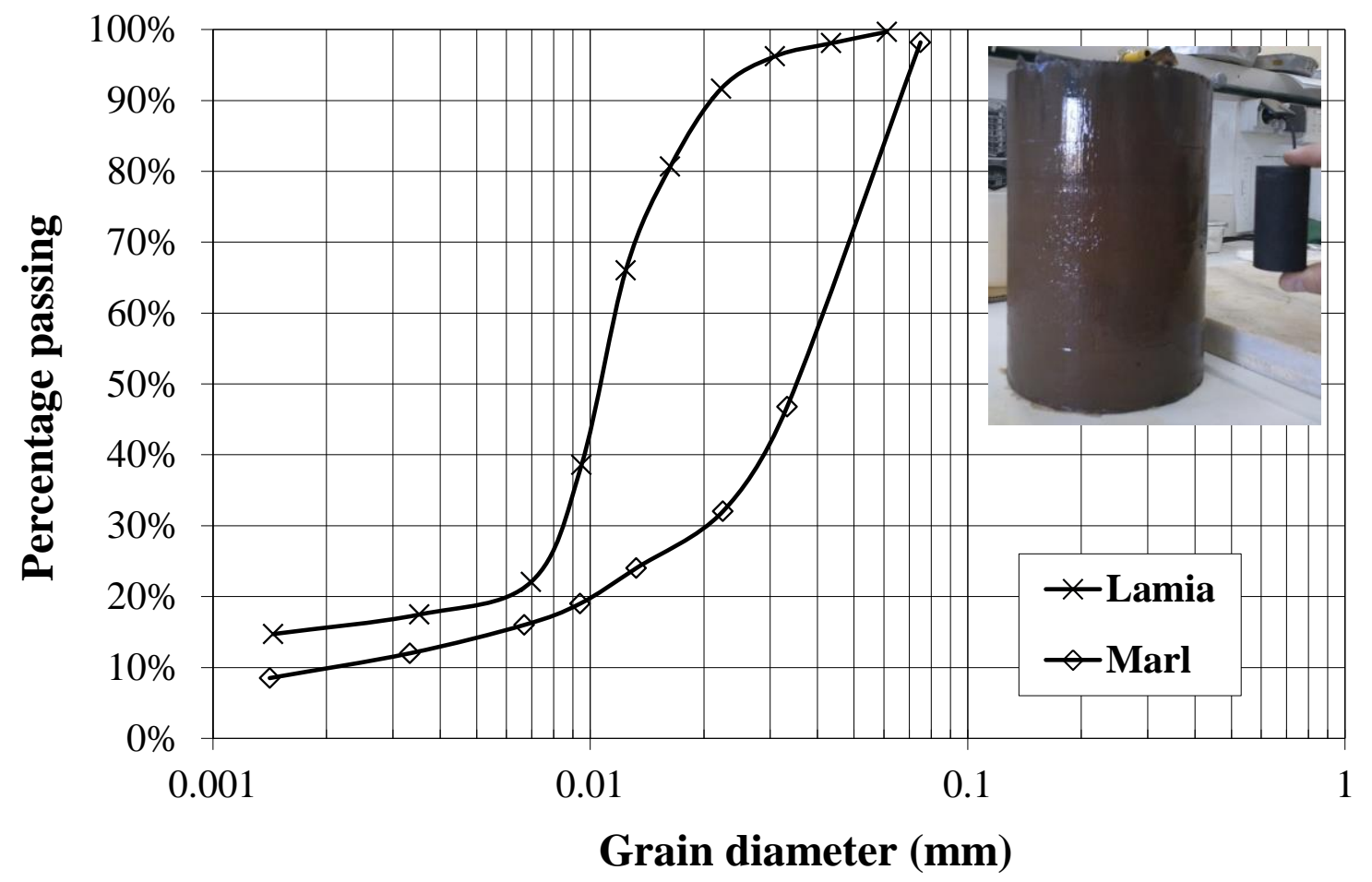

Fig. S1. Grading curves for Lamia and Marl. Inset photograph: Lamia sample after reconstitution in the consolidometer. 


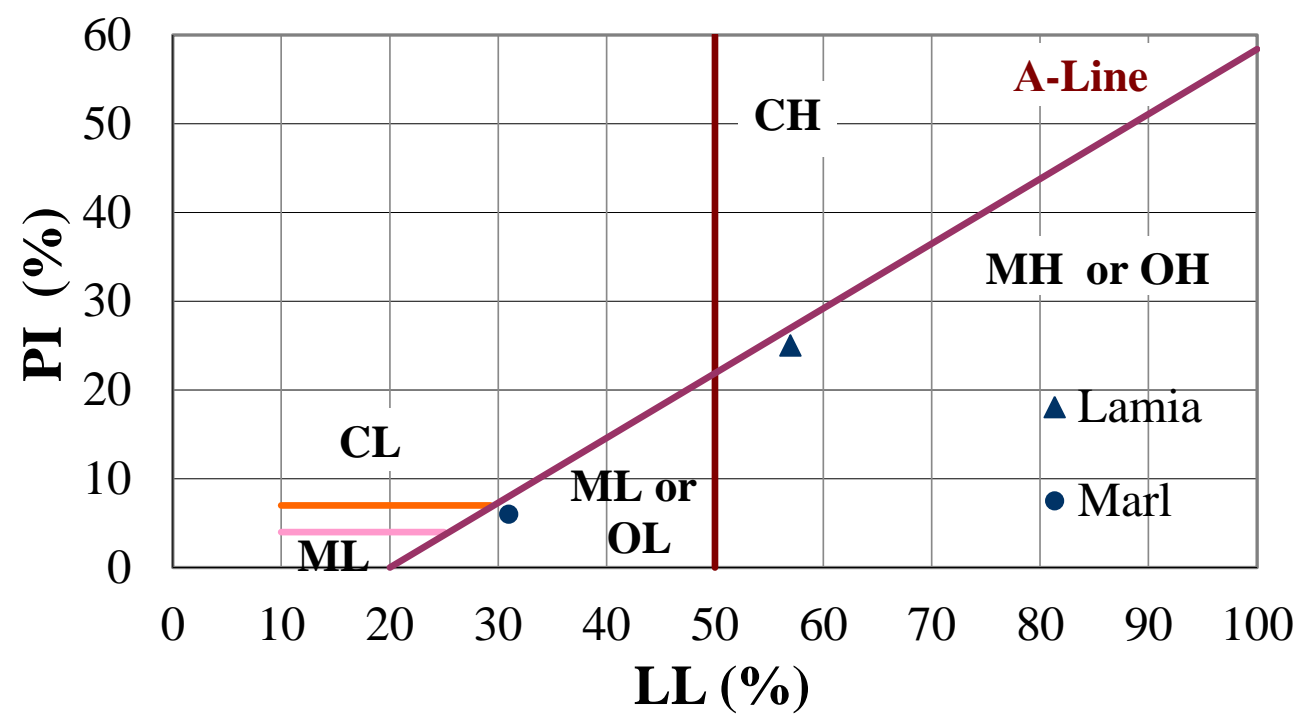

Fig. S2. Plasticity chart 


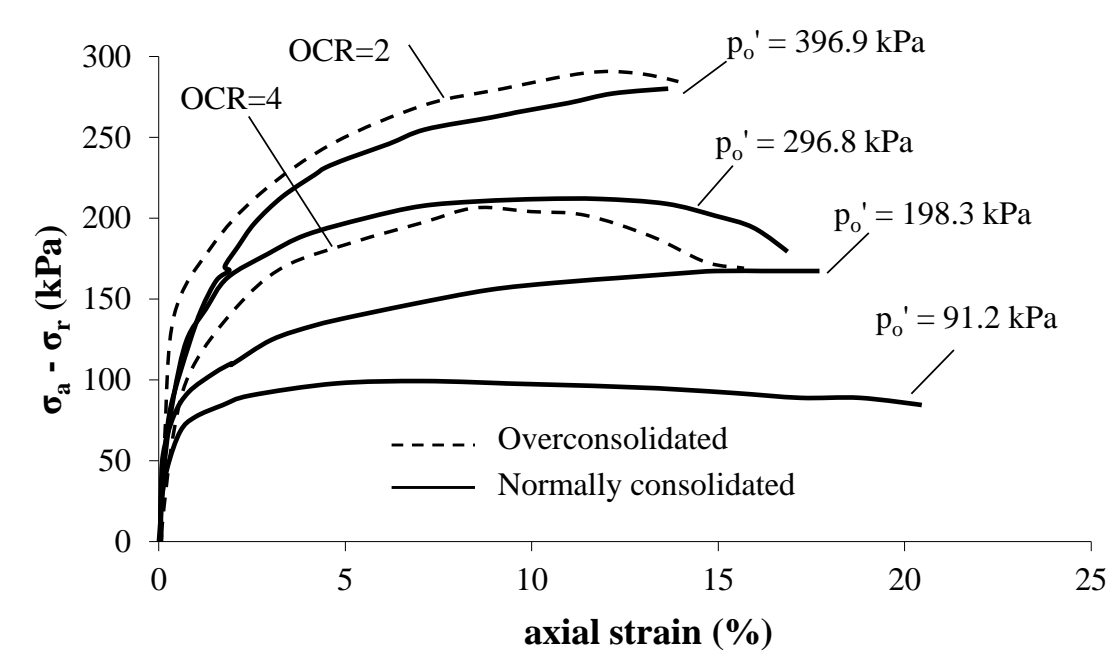

(a)

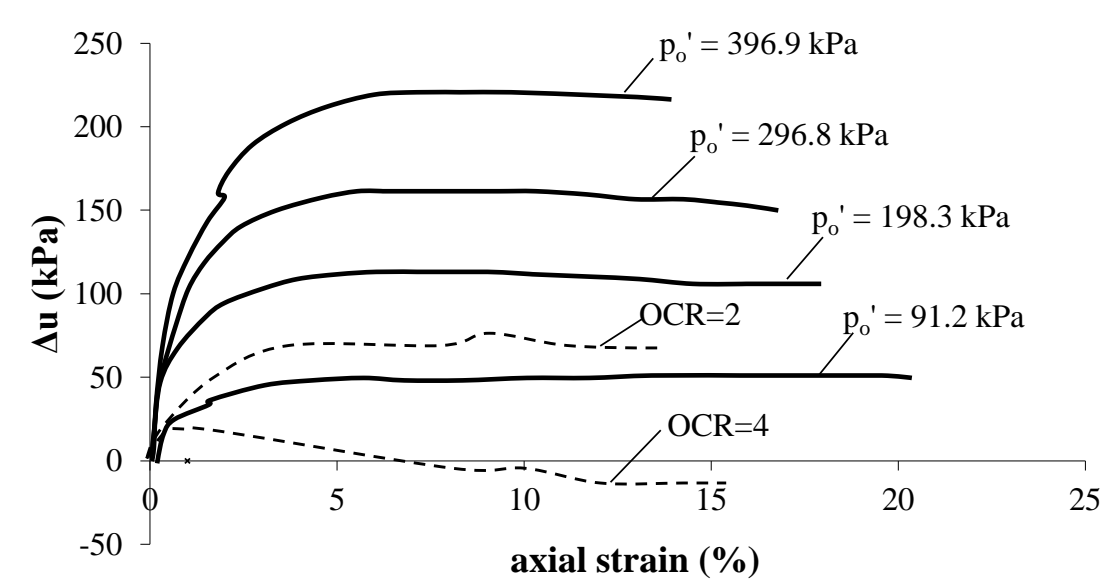

(b)

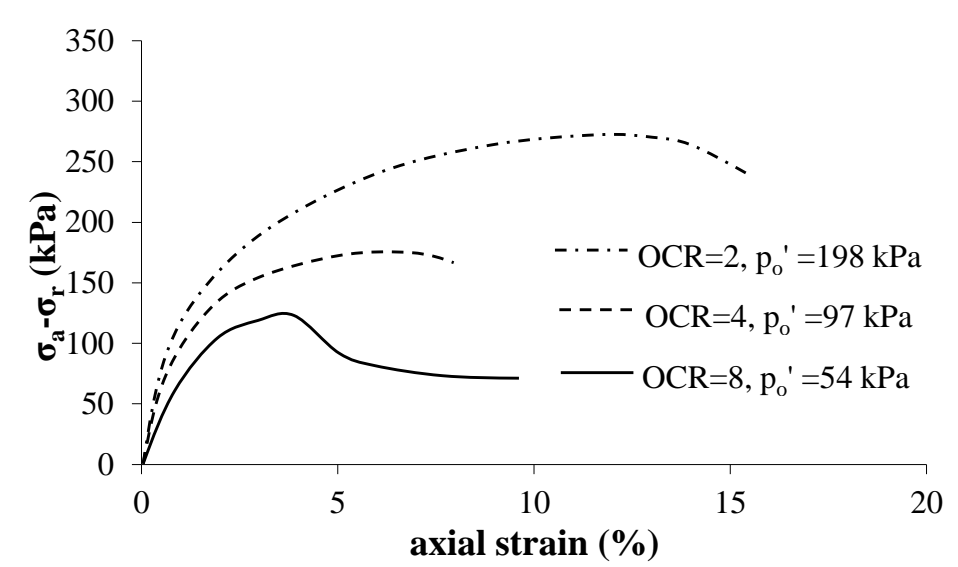

(c)

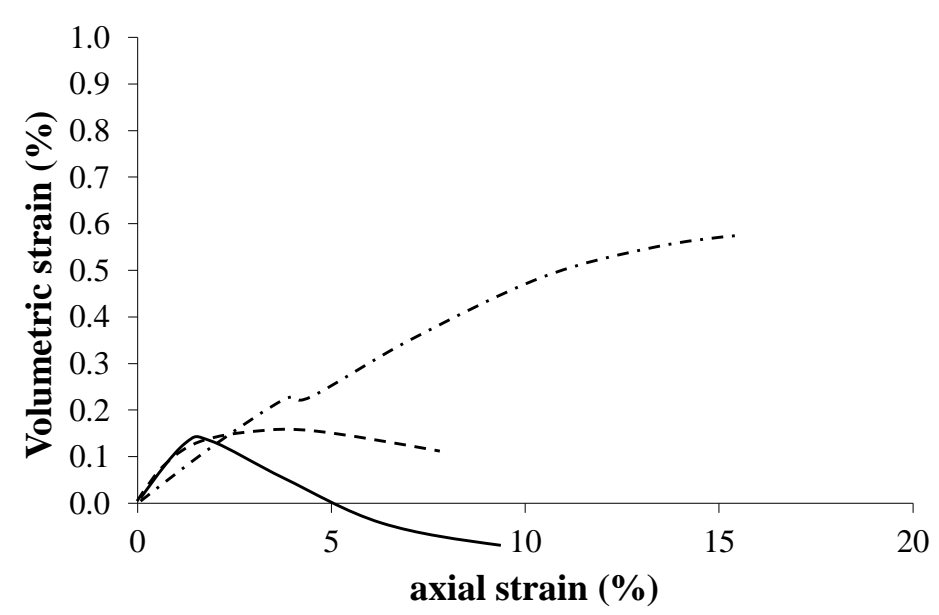

(d)

Fig. S3. Reconstituted Lamia specimens: undrained tests (a) stress-strain curves; (b) excess pore water pressure against axial strain curves; drained tests (c) stress-strain curves; (d) volumetric against axial strain curves 


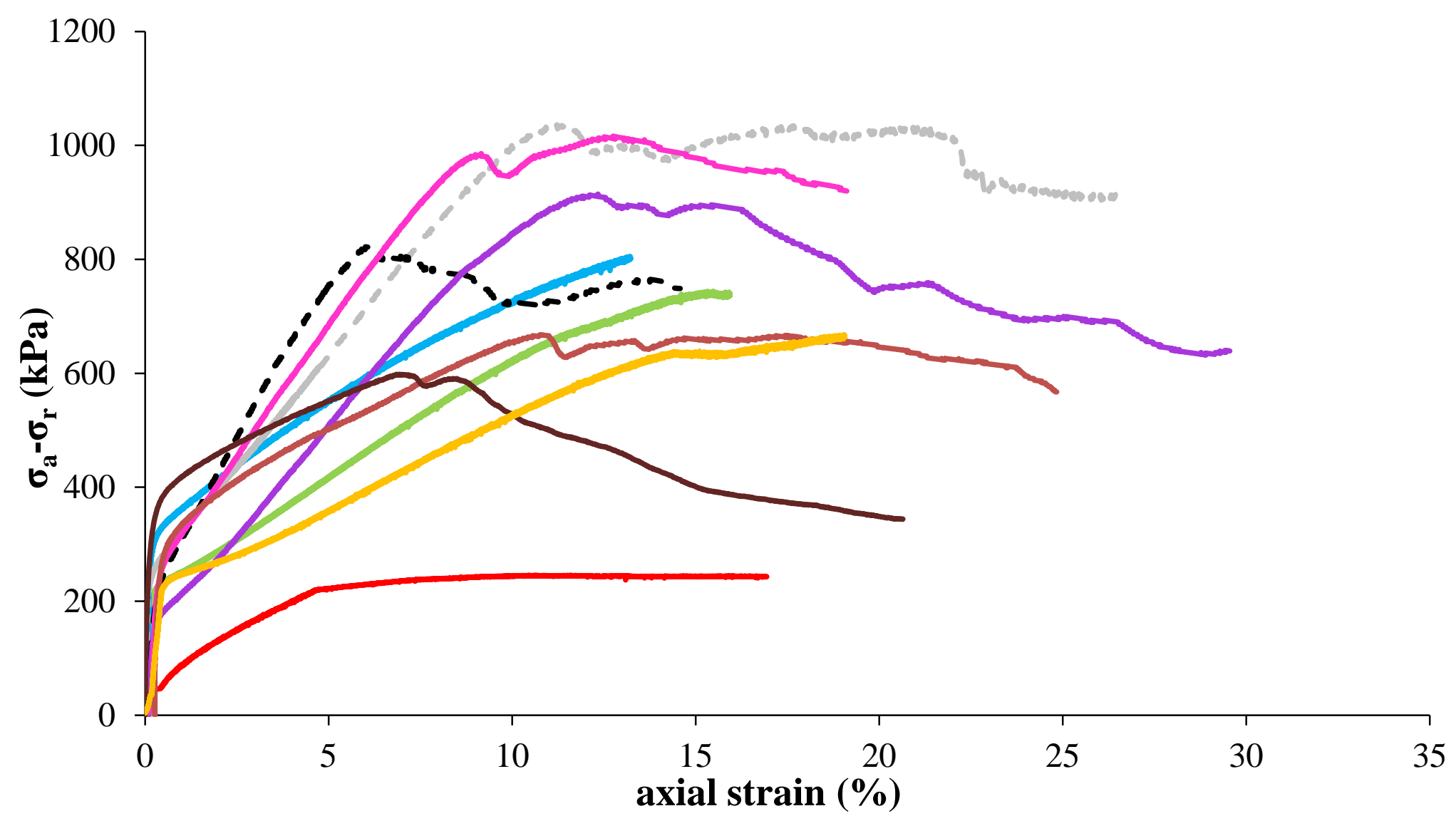

(a) 


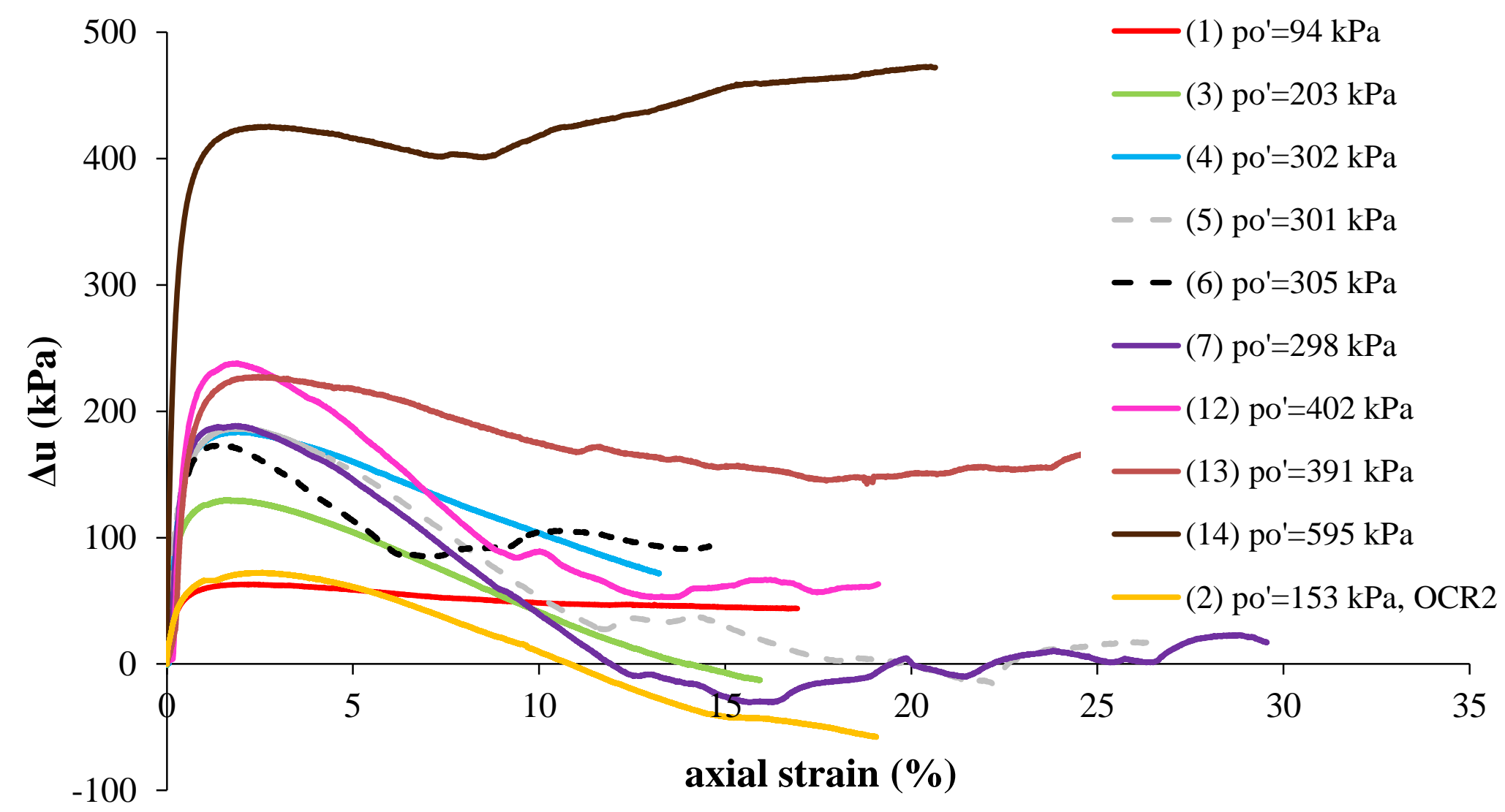

(b) 


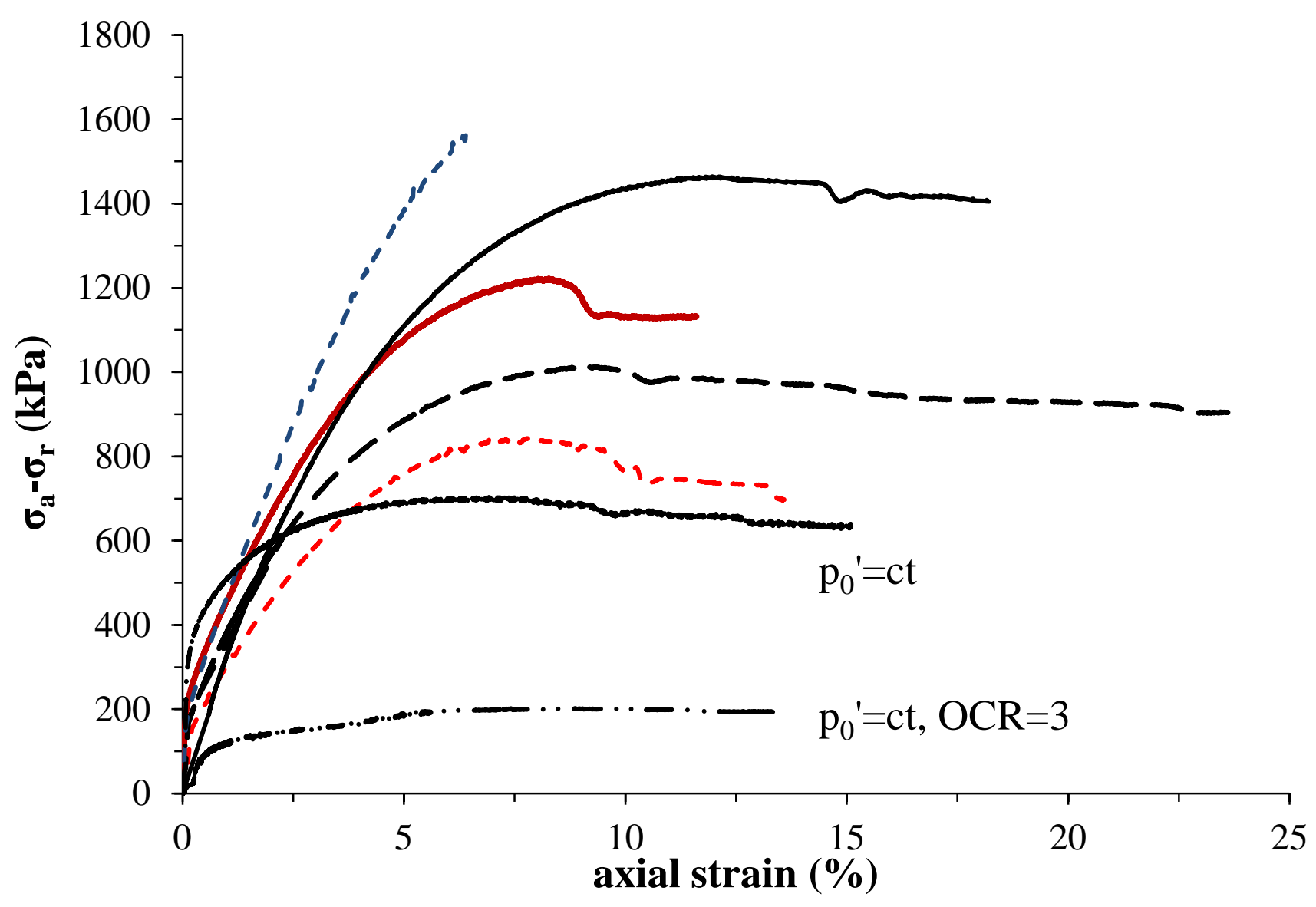

(c) 


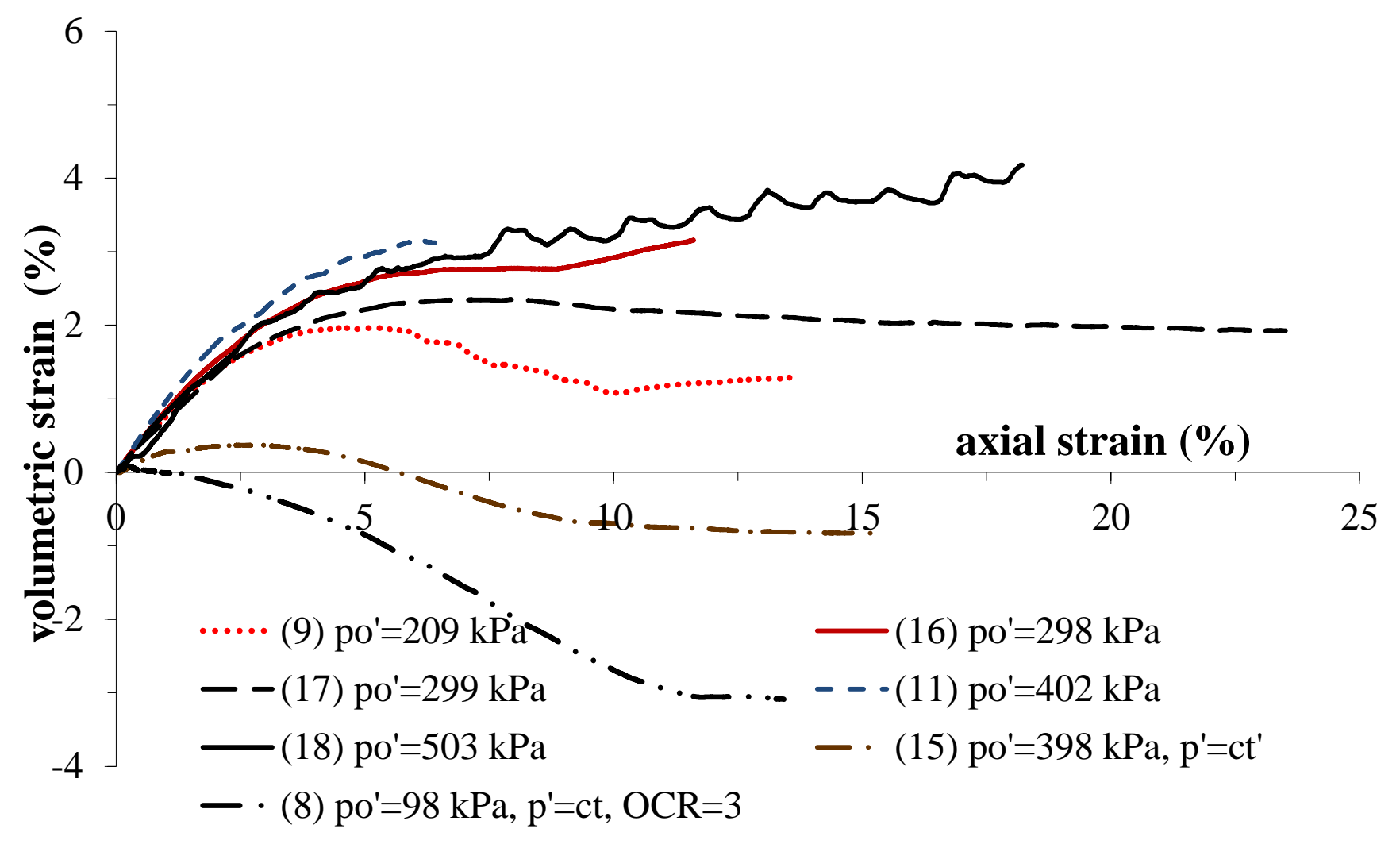

(d)

Fig. S4. Reconstituted Marl specimens: undrained tests (a) stress-strain curves; (b) excess pore water pressure against axial strain curves; drained tests: (c) stress-strain curves; (d) volumetric against axial strain curves 